\title{
Estudio comparativo del impacto en el desarrollo socioeconómico en dos carreteras: Eix Transversal de Catalunya, España, y MEX120, México
}

\section{Comparative study of the impact in the socioeconomic development of two motorways: Eix Transversal de Catalunya, Spain, and MEX120, Mexico}

\author{
Saúl Antonio Obregón-Biosca*
}

\begin{abstract}
Motorways are key to the economic and social development in the territory of any country. Hence, it is important to analyse and compare how motorways provide opportunities for economic and social transformation. This analysis considers two areas with some similarities, but also with evident social differences. To this end, we have selected two motorways in two different countries in order to observe the shortterm effect that each of them has on several socio-economic variables. We have chosen on the one hand the Eix Transversal de Catalunya (Spain) and on the other hand the MEX120 motorway (Mexico). The results show that patterns in the development induced by both motorways are very similar and the main difference is in the level of economic development in each of the territories.
\end{abstract}

Keywords: motorways, land use, mobility, development, socio-economic impact.

\section{Resumen}

Las carreteras son pieza clave en el desarrollo económico y social en cualquier país; por ello, se considera importante analizar y comparar cómo las carreteras proporcionan la oportunidad para la transformación económica y social. Este análisis considera dos ámbitos territoriales con algunas similitudes, pero también con diferencias sociales evidentes. Para ello, se seleccionaron dos carreteras en diferentes países con la finalidad de observar el efecto a corto plazo que tiene cada una en diversas variables socioeconómicas. Se elige por un lado el Eix Transversal de Catalunya (España) y por el otro la carretera MEX120 (México). Los resultados muestran que las pautas en el desarrollo inducido por ambas carreteras son muy similares y la principal diferencia radica en el nivel de desarrollo económico en ambos territorios.

Palabras clave: carreteras, ordenación del territorio, movilidad, desarrollo, impacto socioeconómico.

\footnotetext{
*Universidad Autónoma de Querétaro, México. Correo-e: saul.obregon@upc.edu.
} 


\section{Introducción}

Obtener bienestar colectivo e individual en las comunidades supone el desarrollo de un conjunto de interrelaciones que se pueden englobar en el término socioeconómico. La necesidad de estas interrelaciones, por un lado, y el hecho de que éstas se producen entre personas o empresas que no se localizan en un mismo lugar, por el otro, impulsa a encontrar solución por distintos medios, por ejemplo, el teléfono, el correo, y en especial el transporte con sus infraestructuras.

Las carreteras se consideran factores que permiten el desarrollo económico y social del territorio, su relación es causa-efecto pues hacen posible el desarrollo, aunque no lo provocan directamente. Aunque no provocaran por sí mismas la transformación territorial, inducen a la generación de cambios en los patrones de distribución de la población, además de que apoyan las actividades productivas.

La red de transporte es la mayor decisión estructurante del territorio (Wingo y Perloff, 1961). En este sentido, el efecto estructurador de las carreteras, desde el punto de vista de la ordenación del territorio, determina el sentido del crecimiento fomentando la descentralización demográfica y económica (Plassard, 1978; Navarre y Prud'Homme, 1984; Rephann e Isserman, 1994).

El desarrollo del transporte genera beneficios de eficacia, efectos de transferencia y de relocalización de actividades (Forkenbrock y Foster, 1990; Berechman, 1995). Por su parte, los cambios en la accesibilidad influyen en el crecimiento del empleo y en el comportamiento de los desplazamientos por trabajo. Dicho cambio de accesibilidad en un área dada, incrementa el empleo, lo que causa un futuro económico positivo para la región (Junta de Andalucía, 2000; Universitat de Valencia, 2000; London School of Economics, 2000). Por ello, las carreteras propician un crecimiento económico a lo largo de todo su recorrido, favoreciendo la calidad de vida de la población (Urarte, 1980; Carpintero, 2005; Papí et al., 2006).

Los trabajos pioneros de Von Thünen (1826) y Weber (1909) en la economía de la localización, colocaban el transporte a la vanguardia como distribuidor de las actividades económicas sobre el terreno, sus posiciones han sido ampliadas por estudiosos de la economía de localización: por Lösch (1954), Isard (1956) y Dunn (1954), entre otros autores. Así, el transporte se ha convertido en uno de los elementos principales de las teorías acerca de, por un lado, cómo se distribuyen las actividades económicas y, por el otro, cómo se desarrollan los valores del suelo. Respecto al efecto en los usos de suelo urbano, Badoe y Miller (2000) realizaron una revisión de estudios empíricos sobre la interacción del transporte y 
el uso de suelo en Estados Unidos. Mencionan disparidad en los resultados, ya sea por deficiencias en los datos utilizados o en la metodología, por lo que recomiendan que para estudiar adecuadamente los efectos de los viajes en el territorio o el comportamiento del sistema de transporte en la forma urbana, se use un modelo integral urbano, es decir, que tenga en cuenta a los principales actores, sus interacciones y factores complementarios que impulsan el sistema urbano. El efecto de las infraestructuras se presenta en etapas, como lo observó Sutton (1999), quien analizó el efecto a largo plazo en los usos de suelo inducido por el anillo periférico I-225 en Denver, asimismo observó tres periodos en la evolución de los usos de suelo: el primero, un significativo desarrollo residencial junto con pequeño comercio y oficinas; en el segundo, aumentó la penetración de comercios y oficinas; y en el tercero, el desarrollo de comercios y oficinas alrededor del anillo.

Susan Hanson (1986) relaciona los sistemas de transporte y las dinámicas urbanas. Hace una reflexión alrededor de la elección de la localización residencial y de los lugares de trabajo, que vincula a tres elementos: la topología y la calidad de la vivienda; las características del vecindario y el nivel de accesibilidad. Desde una perspectiva social, Robert Cervero (1999) analizó la accesibilidad a las áreas urbanas mediante las oportunidades de vivienda y trabajo en el área de San Francisco, en relación con la red de transporte. Una de las principales conclusiones a las que llegó este autor es que hay una desigualdad social en relación con la accesibilidad laboral; pues observó que centros laborables de alto nivel son los que tienen un mejor acceso. Menciona que existe una creciente separación de oportunidades laborales y localizaciones residenciales en el proceso de suburbanización norteamericano, que ha perjudicado de manera notable a los estratos sociales más bajos. Cervero (2003) también analizó cómo las inversiones en carreteras estimulan la generación de viajes, empleando la información de 24 autopistas californianas observa que agregar carriles a dichas vías induce el aumento de tráfico debido a la ventaja en las velocidades de los viajes, y cómo estos cambios en las condiciones de funcionamiento influyen en la demanda.

Bérion Pascal (1998) alude que en los años sesenta se pensaba que la construcción de grandes redes de transporte ayudaría de manera importante al desarrollo regional mediante los efectos estructurantes en el territorio, mientras en los años setenta aparecieron numerosos testimonios empíricos (de compleja interpretación), cuyas principales aportaciones se apartaban de los efectos estructurantes y se acercaban más a los factores permisivos. El autor concluye que en las relaciones causa-efecto, las infraestructuras hacen posible el desarrollo pero no lo provocan directamente. Otros autores franceses centran sus estudios en el análisis de la relación 
entre infraestructuras y desarrollo regional, entre éstos se puede citar a François Plassard (1978), quien estudió los efectos estructurantes de las infraestructuras viarias desde el punto de vista de la ordenación del territorio. Dubois-Taine (1991) analizó el efecto estructurante producido por las carreteras en el territorio. Burmeister y Joignaux (1997) recopilaron, en un libro sobre infraestructuras del transporte y territorio, las principales aportaciones sobre la reestructuración territorial debida al sistema de transporte. De acuerdo con algunos de estos autores, se puede concluir que la red viaria no provoca por sí misma la transformación territorial (hablando en términos de desarrollo económico), pero sí induce a que se den cambios en los patrones de distribución de la población y apoya directamente las actividades productivas.

En relación con el impacto económico, una de las obras más completas desde el punto de vista del autor es la de Banister y Berechman (2000), pues abordan el efecto en el desarrollo económico inducido por las infraestructuras de transporte, revisan las investigaciones realizadas hasta entonces en los ámbitos de los efectos económico, social, espacial y ambiental. A la vez, hacen un acercamiento analítico a las técnicas de modelación de los efectos de las infraestructuras de transporte a nivel macroeconómico, en el desarrollo local y el crecimiento económico, así como en la evaluación de proyectos. En este punto, los autores concluyen que la gran mayoría de las investigaciones se han centrado en el efecto macroeconómico; en este sentido mencionan que aunque es posible establecer relaciones estadísticas en este aspecto, es difícil construir relaciones causales que apoyen los datos, como los efectos de factores externos (es decir, en tiempo y fase de desarrollo), pues éstos pueden influir en la dirección y fuerza del efecto. Por último, los autores exponen casos de estudio empírico en relación con el efecto económico de las carreteras, del ferrocarril y de los aeropuertos. Una de las conclusiones más relevantes en el tema que nos atañe es la evidencia indiscutible del papel que juegan los cambios de accesibilidad en el desarrollo económico (por ejemplo, en los cambios demográficos, en la localización de actividades, en el empleo, entre otros).

El aumento de empleo inducido por inversiones en transporte es resultado de la interacción de dos factores principales: el primero es el efecto sobre la voluntad de un trabajador viable de entrar en el mercado de trabajo y viajar al sitio del empleo específico, una vez que los costos del viaje han disminuido. El segundo se relaciona con la demanda de los empleadores y el nivel de acceso a una mano de obra especializada. Berechman y Paaswell (2001) analizan el efecto del cambio de accesibilidad sobre el empleo, conjeturan que mejorando este aspecto en un área dada (resultado de la inversión de una infraestructura de transporte), ésta aumentará su participación en las actividades productivas, dependiendo de 
factores como las características socioeconómicas y de ubicación. Así, examinan el efecto de la mejora de accesibilidad en inversiones de transporte (usando un modelo de ecuación simultáneo) y exploran empíricamente el efecto de los cambios de accesibilidad en el suministro de trabajo en el área sur del Bronx (en Nueva York), un sitio de bajo nivel económico. Esta área ha recibido inversión para mejorar su sistema de transporte: el proyecto Centro del Bronx. Al examinar el factor de la voluntad de un trabajador viable de entrar en el mercado de trabajo y viajar al sitio del empleo específico (después de que los costos del viaje disminuyeron), la investigación demostró el efecto positivo que tiene la reducción del costo de transporte sobre la participación en el mercado de trabajo, y concluyen que el efecto será más profundo en las áreas con población de bajos ingresos, pues para esta población los gastos de participación en el mercado de trabajo (incluido el transporte) constituyen una verdadera barrera para entrar en el mercado. A partir de esta información se establece una correlación clara entre las redes eficientes de carreteras y las oportunidades para el avance económico y social. Así pues, la conclusión común es que las carreteras son uno de los mayores abastecedores de bienestar social y económico.

En este trabajo se analiza y compara cómo las carreteras proporcionan la oportunidad para la transformación económica y social en dos ámbitos territoriales con algunas similitudes, pero que afectan a comunidades socialmente distintas. Para ello se eligieron dos carreteras en diferentes países para observar el efecto a corto plazo en dos territorios que presentan diferencias sociales y económicas: el Eix Transversal de Cataluña (España) y la carretera MEX120 (México). Aunque estas dos vías no tienen el mismo diseño, se eligieron como caso de estudio por las siguientes razones: la puesta en operación de las dos carreteras es contemporánea (en 1994 la MEX120 y en 1997 el Eix Transversal), y al ser relativamente recientes, se dispone de un mayor número de variables estadísticas, lo que nos permite establecer periodos (antes y después de su puesta en operación) para constatar la influencia de ambas vías en el territorio. No obstante, el poco tiempo de explotación de estas dos carreteras limita a enfocarse en sus efectos a corto plazo. Como el objetivo del estudio es comparar el impacto social y económico inducido por cada una de estas vías en sus territorios respectivos, sería deseable que las vías tuvieran características físicas similares (no es de interés en este trabajo comparar el efecto de una autopista con el de una carretera rural), y aunque estas vías no presentan exactamente el mismo diseño, sí comparten características físicas similares, ya que las dos son carreteras de dos carriles (uno por 
sentido de circulación $)^{1}$ y ninguna cobra peaje. Ambas atraviesan territorios que anteriormente contaban con una accesibilidad precaria, el Eix cruza transversalmente la Cataluña central, pasa la Sierra del Estany, el Montseny y Les Guilleries; mientras la carretera MEX120 recorre el estado de Querétaro de sur a norte cruzando la Sierra Madre Oriental. Otro punto de interés por el cual se escogieron carreteras de diferentes países, es observar el efecto que tiene una carretera en dos territorios que presentan diferencias sociales y económicas evidentes, pues mientras el Eix Transversal se localiza en un país desarrollado, la MEX120 se ubica en un país en vías de desarrollo, por lo que se podrá observar hasta qué grado una carretera impulsa el desarrollo de una región.

\section{Delimitación de los ámbitos de estudio}

Para determinar los municipios ${ }^{2}$ que están directamente vinculados con la vía (incluyendo aquéllos por donde transcurre físicamente el trazado), se seleccionaron tomando en cuenta la distancia real por carretera, considerando el principal núcleo de población de cada municipio hacia su acceso más cercano a la vía, y se fijó la distancia máxima entre estos dos puntos en 10 kilómetros.

En el Eix Transversal se estudia el tramo carretero que comprende los municipios de Manresa y Vilobí de Onyar, con un total de 103 km y que afecta directamente a 39 ayuntamientos (mapa I).

Por su parte, en la carretera MEX120 se analiza el tramo de San Juan del Río a Xilitla, que abarca $280 \mathrm{~km}$ que transcurren por los estados de Querétaro de Arteaga y San Luis Potosí, favoreciendo directamente a 10 municipios (mapa II).

\section{Procedimiento metodológico}

Para realizar el estudio y comparar el efecto socioeconómico inducido por cada una de estas carreteras, se empleó el método clásico de evaluación ex-ante y ex post, es decir, se observa la evolución de diversos indicadores socioeconómicos antes y después de la construcción de la infraestructura: estos indicadores son: 1) el aspecto demográfico analiza la evolución de la población y los saldos migratorios; 2) la cuestión económica estudia la evolución de las actividades productivas, la renta familiar, el PIB, las actividades financieras, entre otras; 3) el tema laboral examina la evolución de la ocupación por sector de actividad; y 4) el efecto urbanístico estudia

\footnotetext{
${ }^{1}$ En el caso del Eix Transversal, la vía cuenta en algunos tramos con un tercer carril para tránsito lento.

${ }^{2}$ Unidad básica de la división político-administrativa en los dos países.
} 


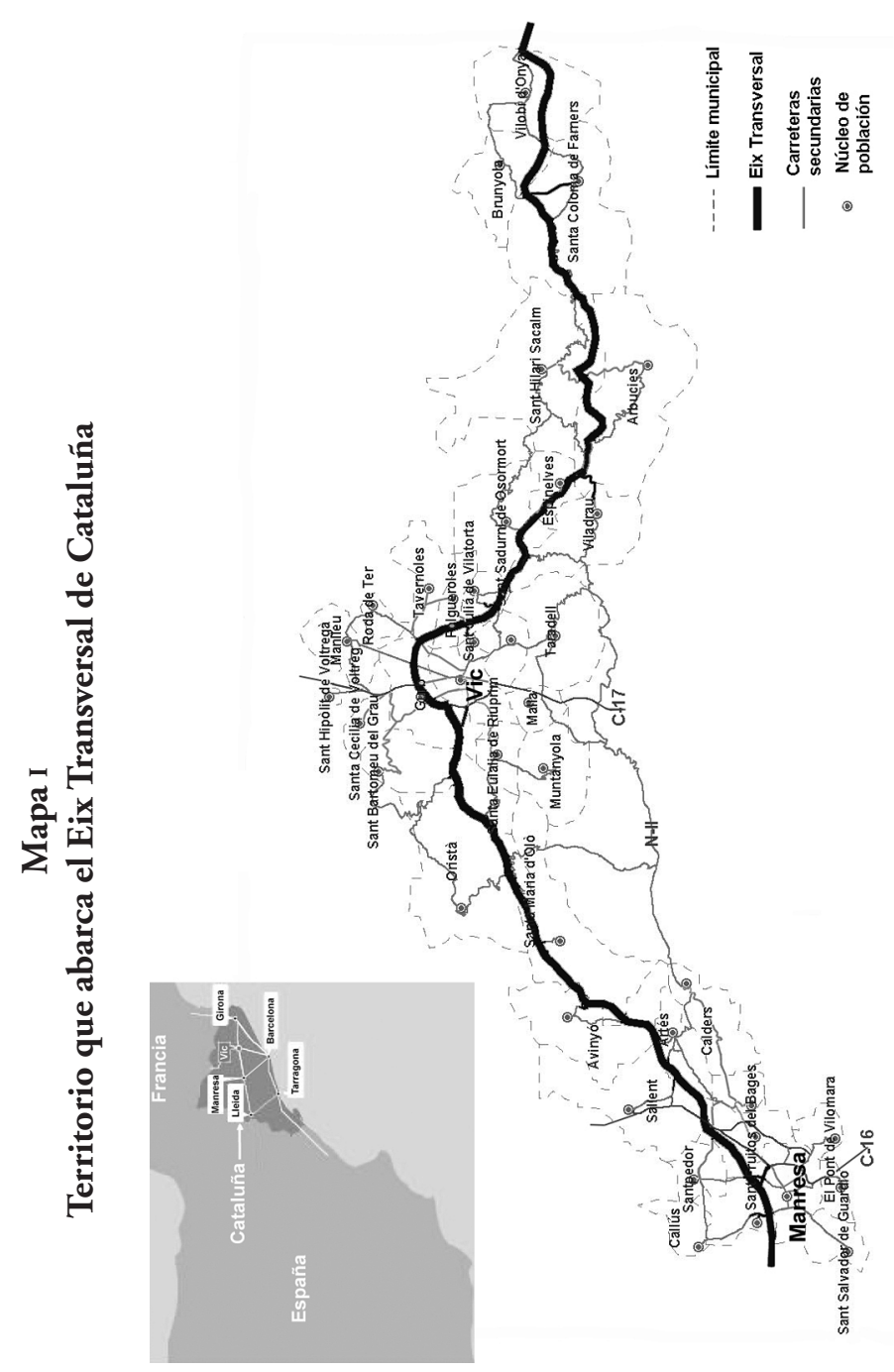




\section{Mapa II \\ Territorio que abarca la carretera MEX120}

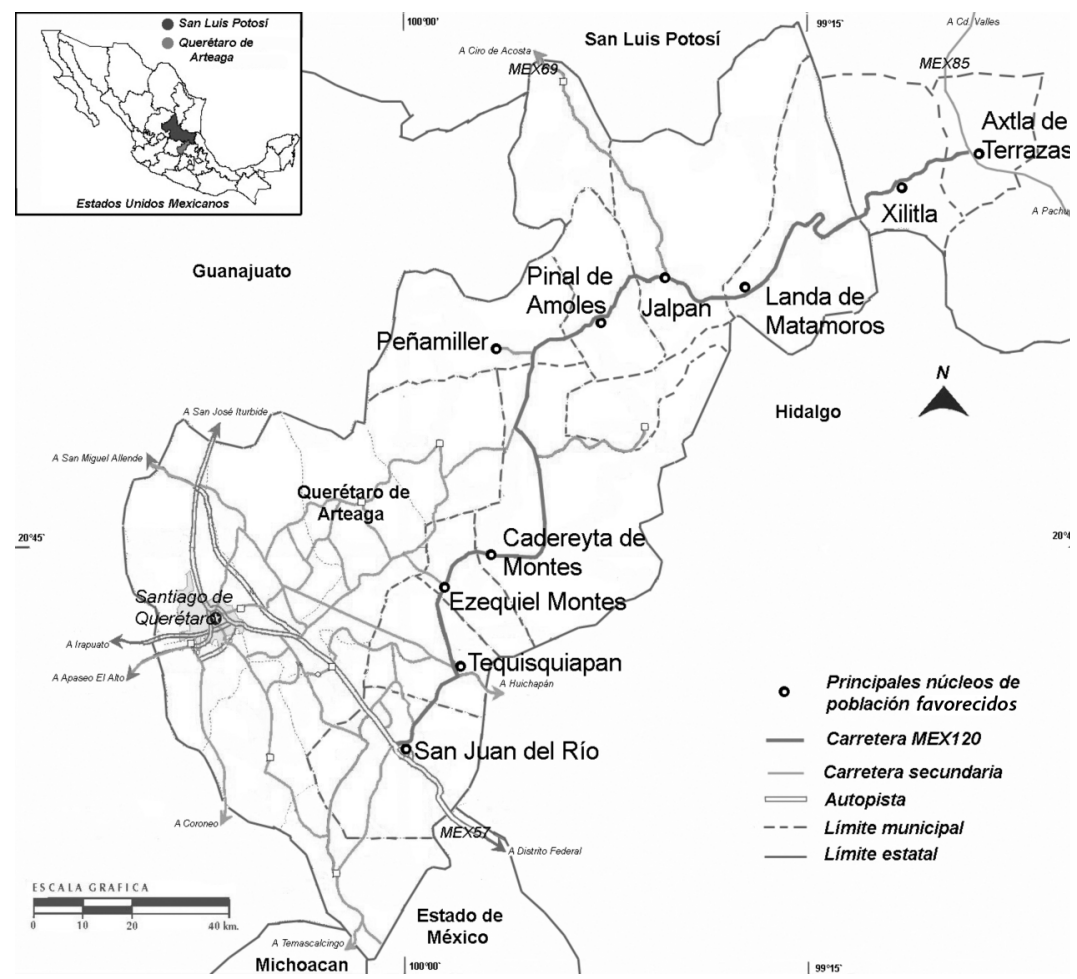

Fuente: Elaboración propia a partir del mapa de carreteras estatal de la Secretaría de Comunicaciones y Transportes de México.

la evolución del parque residencial y las variaciones en la superficie empleada por los establecimientos económicos. En el impacto en el tráfico y la movilidad se examina la evolución del parque vehicular y de la intensidad media diaria (IMD) de la vía, además de la valoración económica de ahorro de tiempo y carburante.

Para llevar a cabo la comparación en ambos territorios se utilizó información estadística de institutos oficiales e instituciones bancarias. Así, los datos empleados en el caso de estudio del Eix Transversal se obtuvieron del Instituto de Estadística de Cataluña (Idescat) y del Anuario Económico de España de La Caixa; para analizar el ámbito territorial de la MEX120 se utilizó información del Instituto Nacional de Estadística, Geografía e Informática de México (INEGI).

Cabe mencionar que la evolución de las variables analizadas en cada ámbito territorial se comparan con su nivel político-territorial superior 
en busca de sinergias, esta referencia ayuda para localizar alguna tendencia global para que no se construya la vía, al momento de evaluar cada municipio y su conjunto. Así, en el caso del ámbito territorial del Eix Transversal, éste se compara con la Comunidad Autónoma de Cataluña, mientras en el caso de la MEX120 se compara con los estados de Querétaro y San Luis Potosí.

Con el objetivo de comprobar la existencia o no de elementos distorsionadores, así como observar si se presentan o no pautas en el desarrollo de los municipios teniendo en cuenta su ubicación o tamaño poblacional, se emplean cuatro variables de control: 1) el tamaño de población municipal nos permite identificar la dinámica poblacional, y además nos indica si la vía influye de manera diferente en los municipios más pequeños respecto de los medianos o grandes; 2) la distancia a una ciudad central permite observar el grado de suburbanización o dependencia de los municipios, para poder determinar si el desarrollo de éstos está ligado al hecho de ubicarse cerca de una ciudad central (Manresa y Vic en cuanto al Eix Transversal, y San Juan del Río en el de la MEX120); 3) la distancia entre el principal núcleo de población municipal a la vía de estudio, variable que permite definir el área de influencia de la carretera, así como establecer qué efecto tiene su cercanía; y 4) la distancia a otra vía principal de igual o superior categoría a la del análisis, lo que permite observar el grado de influencia en cuanto a si la proximidad de otra vía importante contribuye en el desarrollo.

\section{Efectos socioeconómicos inducidos por el Eix Transversal de Cataluńa}

El Eix Transversal de Cataluña se concibió como una alternativa a los ejes radiales que confluyen en el área metropolitana de Barcelona, pensado para reequilibrar el sistema urbano y territorial de Cataluña central y mejorar en el acceso a dicha región. A lo largo de esta investigación se deduce que el objetivo se cumplió.

Por la variación en la recopilación de datos, el análisis de la etapa previa a la construcción de la vía, en algunas variables se efectúa a partir del año 1986 y en otras a partir de 1991, mientras que el periodo de construcción abarca de 1991 a 1996, y la etapa de explotación va de 1996 a 2007.

\subsection{Efecto en la demografía}

El análisis demográfico en la zona que abarca el Eix Transversal muestra que antes del inicio de las obras, la población aumentó 8,530 habitantes. Ahora bien, en el periodo de construcción (es decir, entre 1991 y 1996) 
la población aumentó 4,065 habitantes (figura I). Wang (2002), entre otros autores, considera el efecto demográfico como indicador del impacto global de las carreteras sobre el medio en el que se construyen. Así lo constata este estudio, pues en el periodo de explotación de la vía (entre 1996 y 2007) su población aumentó 41,658 habitantes, esto representa un crecimiento de $20.4 \%$, mientras que en Cataluña fue de $18.4 \%$ en el mismo periodo.

El crecimiento demográfico en el ámbito territorial del Eix Transversal se debe principalmente a la inmigración, si bien no se dispone de esta información hasta el año 2007, se observa que entre 1996 y 2001 el saldo migratorio constituyó $92 \%$ del crecimiento total, ésta procede de otros municipios de Cataluña (6,900 personas) y del extranjero $(7,633)$, y se estableció sobre todo en las ciudades centrales y en sus municipios cercanos, pues buscan empleo en estas aglomeraciones (figura I).

\subsection{Efectos en la actividad económica}

\subsubsection{En los sectores industria, servicios y comercio}

La mejora en el acceso del ámbito territorial del Eix Transversal ha influido en la disminución de los costos de transporte, por lo que esta vía ha favorecido la instalación de nuevas empresas industriales. En este sentido, Durán-Fernández (2008) menciona que la accesibilidad tiene un efecto directo en los niveles de productividad, pues se refleja en costos de transporte más bajos. Así, el estudio reveló que en el periodo 1996-2002 se establecieron 126 nuevas industrias, 5\% más (figura II); en tanto que Cataluña registró la pérdida de $1 \%$ de sus establecimientos durante el mismo periodo. Esto confirma que el nivel de dotación de carreteras tiene una influencia directa en la elección del lugar de emplazamiento, lo cual se aprecia en los municipios localizados en la cercanía de otras infraestructuras viarias de importancia regional, pues estos municipios presentan un mayor crecimiento en su número de establecimientos. En este sentido, Holl (2004), a partir de un estudio en el que combina el empleo de datos a nivel micro y técnicas sIG (sistema de información geográfica), observó el efecto de nuevas infraestructuras viarias en la ubicación de nuevos establecimientos manufactureros en municipios españoles, asimismo menciona que las nuevas autopistas afectan la distribución espacial de los establecimientos, no obstante difiere dependiendo del sector y el espacio, es decir, la proximidad a empresas del mismo sector indica que la especialización también ha sido una fuerza relevante.

Al hacer el análisis de la evolución de los establecimientos del sector servicios, se observa que el ámbito territorial del Eix Transversal aumen- 


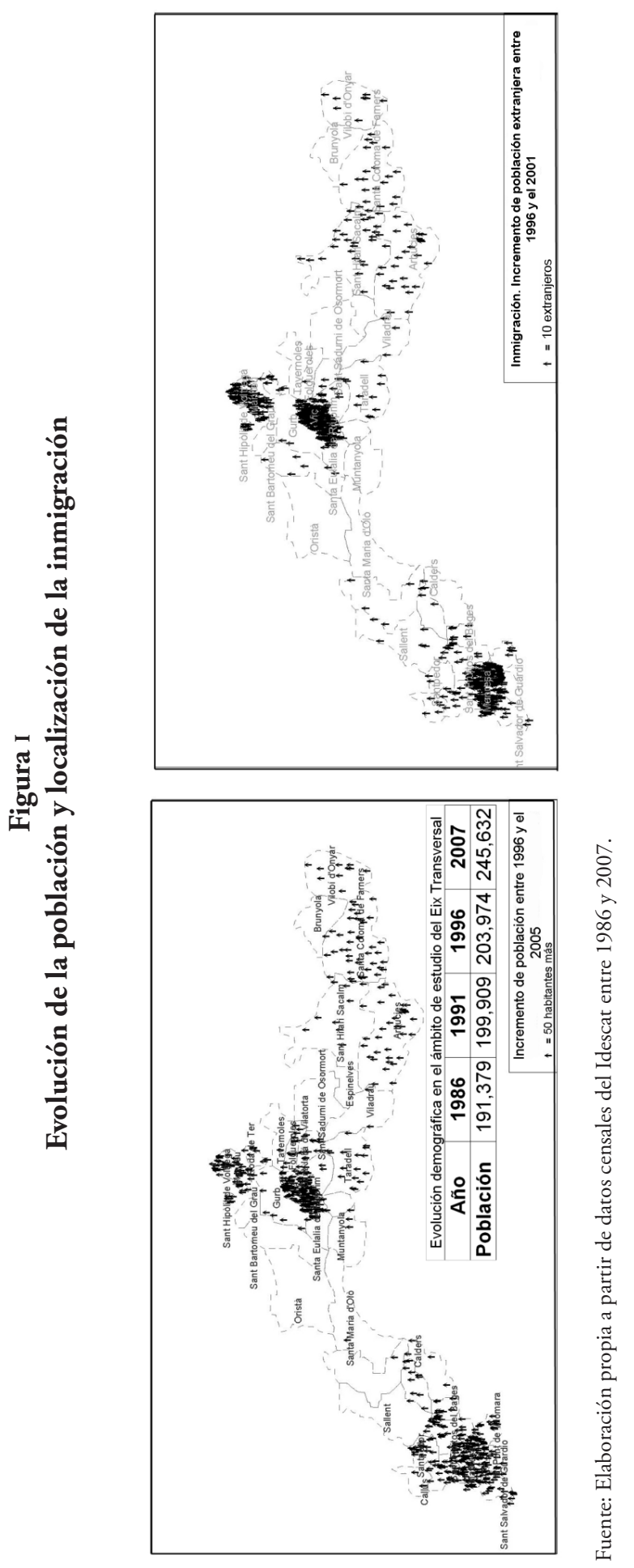




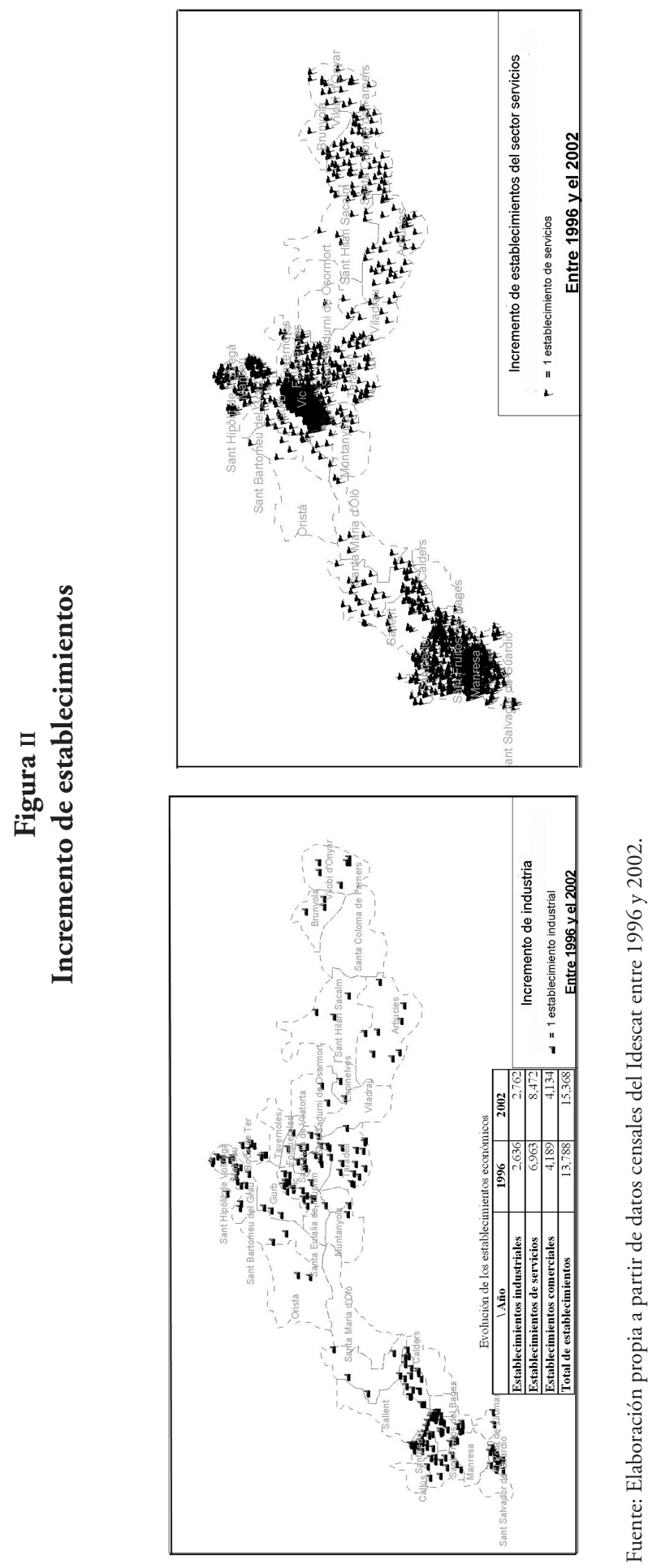


tó sus establecimientos de servicios, durante 1996-2002, en 1,509 empresas (22\%), en contraste, Cataluña aumentó $19 \%$ en ese rubro en el mismo periodo.

Por lo que se refiere al sector comercial, el conjunto de municipios que se encuentran en el Eix Transversal muestran una disminución de 55 establecimientos en el periodo 1996-2002 (-1\%); ahora bien, en Cataluña durante el mismo periodo el número de establecimientos comerciales decreció 5\%. Por lo anterior se puede afirmar que la influencia del Eix Transversal ha contenido la pérdida de establecimientos comerciales y por ello, en el ańo 2002, el ámbito de estudio muestra una relación de 17.5 establecimientos comerciales por cada mil habitantes, en tanto que en Cataluña es de 15.84. Así, partiendo de los resultados obtenidos en el análisis de la evolución de los establecimientos económicos, se puede decir que el Eix Transversal apoya directamente las actividades productivas, pues se aprecia un mayor impulso en el territorio analizado respecto a Cataluña.

\subsubsection{En la mano de obra}

Otro punto importante es la creación de puestos de trabajo. En este sentido, la investigación reflejó que en el periodo ex-ante (1991-1996) la población activa ocupada en el ámbito de estudio se incrementó en 68 ocupados (figura III), mientras en el periodo ex-post (1996-2001) aumentó el número de ocupados en 19,964 trabajadores. Así, se constata que el incremento de accesibilidad induce la participación y reorganización del empleo, lo que a su vez causa un futuro económico más positivo para el área favorecida por la infraestructura.

La población ocupada en el sector primario disminuye en ambos periodos, en $0.9 \%$ en el periodo ex-post debido principalmente al empleo de nuevas tecnologías. Ahora bien, la misma tendencia (aunque más marcada) se observa en Cataluña con $-23 \%$. En cuanto a la ocupación en el sector industrial, decrece en el periodo de construcción de la vía, sin embargo, en la etapa ex-post repunta, mostrando un crecimiento de $6 \%$ respecto a 1996, superando el crecimiento de Cataluña de 0.2 por ciento.

El sector de la construcción en el periodo ex-ante disminuyó su número de ocupados, no obstante, en el año 2001 este sector registró la tasa de crecimiento más alta del periodo ex-post en los cuatro sectores estudiados, con $82 \%$. El sector servicios presenta un crecimiento de $36 \%$ en el periodo ex-post, no obstante, este sector al igual que el de la construcción no supera la tasa de crecimiento catalana (de 37\% para el sector servicios y $89 \%$ para el de la construcción). En este sentido hay que tener en cuenta que la Región Metropolitana de Barcelona (RMB) es un gran cen- 


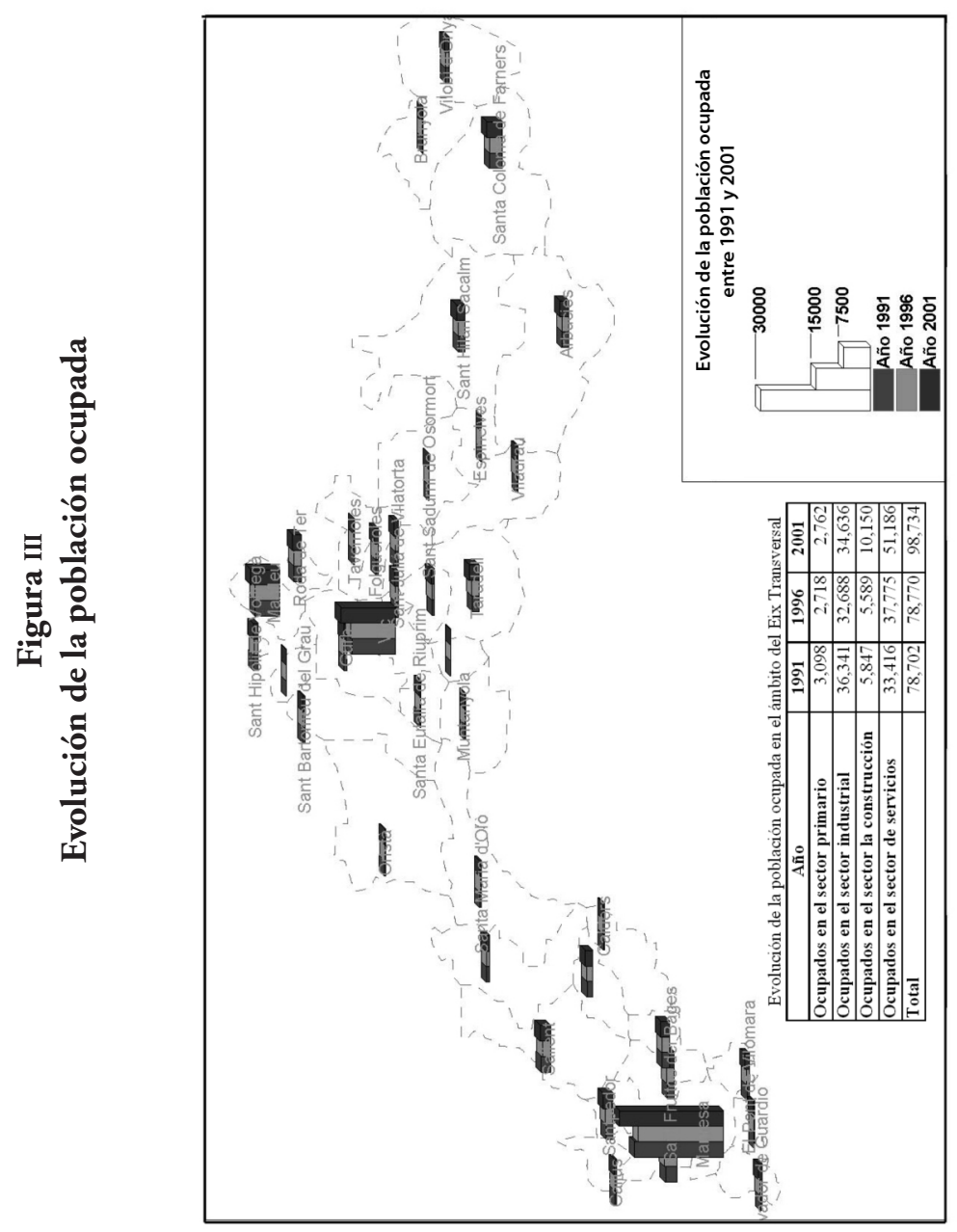

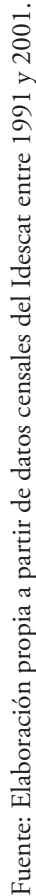


tro de atracción, si se hace el cálculo sin la RMB se ven más claramente los efectos del Eix, tanto en empresas como en población ocupada.

\subsubsection{Variación del producto interno bruto y la renta familiar}

La investigación muestra que el Eix Transversal ha influido en su territorio el establecimiento de nuevas empresas, lo que a la vez ha provocado el aumento de población económicamente activa ocupada. Estos factores han generado que el рів de los municipios analizados pasara de 2,370 millones de euros en 1996, a 2,817 millones en el año 2001, es decir, se incrementó $19 \%$ en el periodo ex-post, en tanto que el PIB en Cataluña aumentó $16 \%$. Otro aspecto a tener en cuenta es la evolución de la renta familiar (indicador cuyo propósito es medir la capacidad económica de las familias o personas), la cual se ha incrementado en todos los municipios estudiados, que en conjunto muestran un aumento en su renta familiar por habitante entre 1996 y 2001 de 18.9\% (pasó de una media de 9,338 euros a 11,103 euros anuales). No obstante, cabe destacar que Cataluña pasa de 9,400 a 11,200 euros anuales, lo que refleja un crecimiento similar al del ámbito de estudio.

\subsubsection{Variación del número de oficinas bancarias}

El análisis de la evolución de las oficinas bancarias es importante para los fines de esta investigación, en cuanto que nos muestra cómo ha cambiado el nivel de desarrollo económico. En este sentido, el ámbito de estudio pasó de 231 oficinas bancarias en 1997 a 252 en el año 2005. El estudio refleja una mayor tasa de crecimiento en el periodo ex-post del número de oficinas bancarias en el ámbito de estudio respecto a Cataluña (de $9 \%$ en los municipios favorecidos, frente a $5 \%$ de la Comunidad Autónoma). Por lo anterior, el área de estudio superó a Cataluña en su relación de número de oficinas por habitante, pues en el año 2005 era de 1.11 oficinas bancarias por cada mil habitantes, en tanto que en Cataluña era de 1.04 .

\subsection{Efectos sociales}

\subsubsection{En la construcción de viviendas}

En lo que respecta a la vivienda, el crecimiento demográfico provocó una demanda de hogares para albergar a los nuevos residentes, el análisis muestra un crecimiento de 11,215 nuevas viviendas entre 1991 y 1995 , mientras en el periodo ex-post (1996-2005) se construyeron 45,176, es 


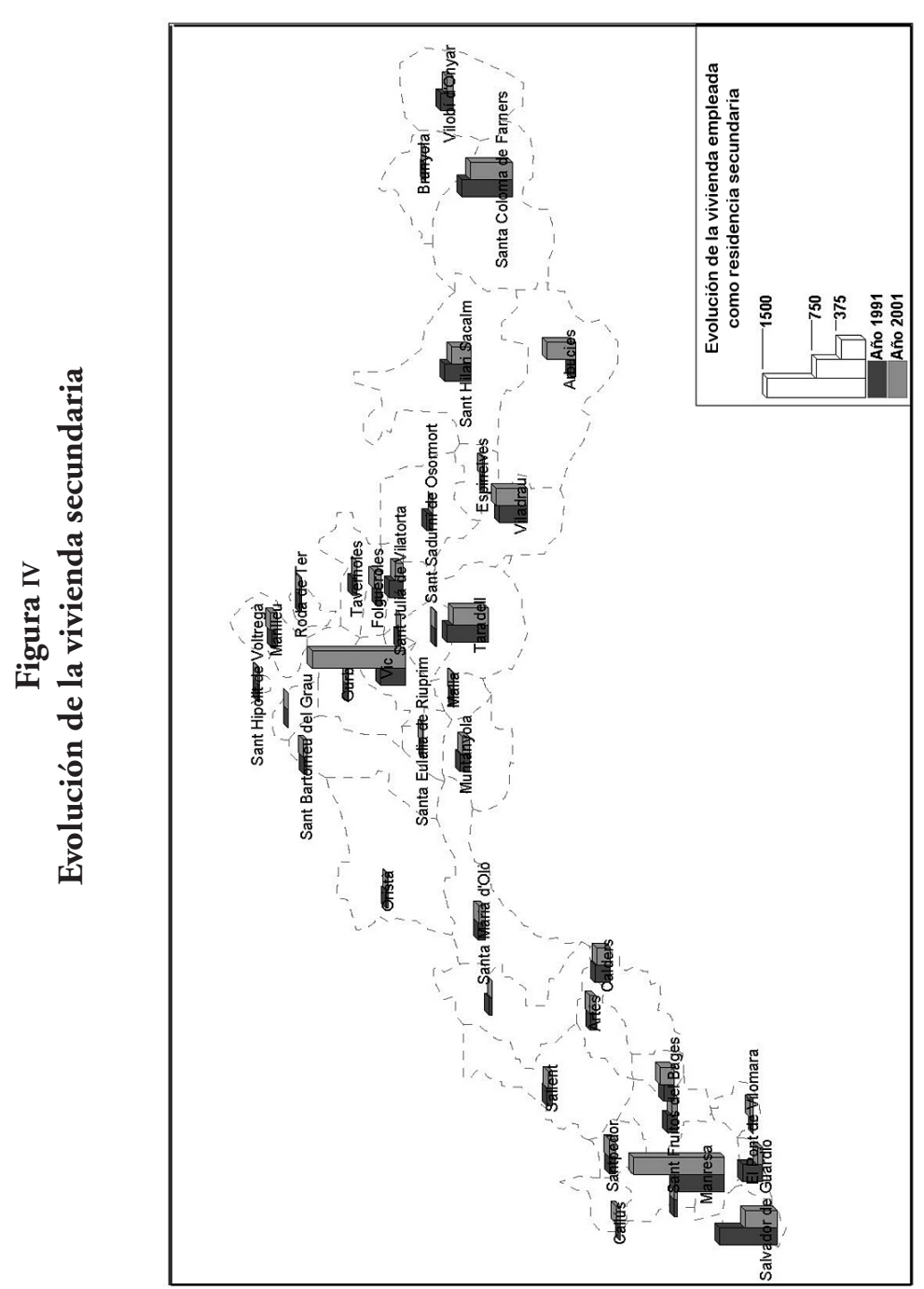

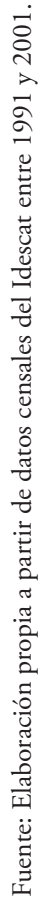


decir, 303\% más respecto a las construidas en el periodo ex-ante, por lo que es significativo el aumento en las dos ciudades centrales y en los municipios cercanos a ellas. Cabe destacar que la tasa de crecimiento del ámbito territorial supera el aumento mostrado por Cataluña en el mismo periodo (de 289\%).

Otro punto de interés es la evolución de la vivienda secundaria. El estudio arrojó que en el año 2001 había 7,516 viviendas registradas como secundarias, mientras que en 1991 la cifra alcanzaba 6,729 (figura IV). En este sentido, los aumentos más considerables se presentaron en los municipios de Manresa y Vic principalmente, seguidos de municipios con interés turístico como Viladrau, Navarcles, Callús, Folgueroles y Manlleu.

\subsubsection{En la expansión de centros educativos}

Otro aspecto que se analizó fue la evolución del número de centros de enseñanza y de personal docente, tanto públicos como privados (de los niveles infantil, primario, secundario y especial). Coincidiendo con lo dicho por Urarte (1980: 213), el equipamiento urbano es primordial para la atracción de población, por lo que es necesario que las escuelas se localicen a poca distancia del lugar de residencia.

La investigación muestra un incremento de centros de enseñanza influenciados por el reciente crecimiento demográfico, en el periodo ex-post, el número de estos centros se incrementó en 10.3\% (cuadro 1), concentrados principalmente en los municipios de Manresa, Vic, Sant Fruitós del Bages y Santpedor. Ahora bien, el profesorado de los centros de enseñanza aumentó $10.6 \%$ en el mismo periodo.

\section{Cuadro 1 \\ Evolución de los centros educativos y personal académico}

\begin{tabular}{lrr}
\hline \multicolumn{1}{c}{ Año } & 1996 & 2004 \\
\hline Centros educativos & 145 & 160 \\
Profesores & 2,955 & 3,269 \\
\hline
\end{tabular}

Fuente: Elaboración propia a partir de datos del Idescat (1996 y 2004).

Estos resultados permiten exponer que el Eix Transversal influye en la extensión y alcance de este servicio cultural, no obstante, el punto que se considera clave en el efecto inducido por la vía es la instalación de dos centros de investigación (para que esto suceda, es necesario que se cuente con buen acceso, proximidad a centros industriales, tecnológicos y universidades). El ámbito de estudio cuenta con tres instituciones de 
educación superior: la Universidad de Vic (reconocida en 1997) y los campus de la Universidad Autónoma de Barcelona y de la Universidad Politécnica de Catalunya, en Manresa, en este último municipio es donde se han instalado dos centros de investigación: el Centre Tecnològic de Manresa en $2004^{3}$ y el Parque Tecnológico de la Catalunya Central (que se tenía previsto abriera en 2008).

\subsubsection{En la atracción turistica}

Leralta (1991), Sachs (1992) y Dupuy (1995) coinciden en que la accesibilidad es un punto clave en el desarrollo del sector turístico, pues una carretera permite acceder a sitios atractivos para vacacionar desde un fin de semana hasta periodos más largos.

El análisis emplea el índice turístico del Anuario Económico de España (2006) editado por La Caixa, el cual se considera un indicador de la oferta turística (pues categoriza los establecimientos turísticos como hoteles y moteles, hostales y pensiones, entre otros, e incluye el número de habitaciones y la ocupación de éstas). El estudio en el ámbito territorial reveló que entre 1999 y 2005 el índice pasó de 86 a 122 puntos, se trata pues, de un aumento de $41.9 \%$, en tanto que este índice en Cataluña sólo se incrementó $0.4 \%$ en el mismo periodo. Los municipios que presentan mayor variación en dicho índice son las dos ciudades centrales y los municipios que cuentan con atractivos naturales o se localizan cerca de éstos (como los ubicados en la región del parque natural del Montseny y en el de Les Guilleries).

\subsubsection{En el suelo urbano ocupado por actividades económicas}

Los usos de suelo se transforman de acuerdo con las nuevas demandas de agentes económicos, sobre todo cuenta la oferta contenida en los planes de urbanismo municipales, por ello la superficie empleada por el sector industrial en el ámbito de estudio se incrementó en el periodo ex-post $16 \%$ (cuadro 2), mientras que en Cataluña aumentó $9 \%$ en el mismo periodo. En cuanto a las empresas del sector servicios, crecieron $20 \%$, y en Cataluña $20.5 \%$. Hay que considerar que tanto la RMB como la zona de costa ejercen gran atracción en este tipo de establecimientos, por lo que si no se le considera se observaría la influencia del Eix Transversal de forma más evidente.

\footnotetext{
${ }^{3}$ Que depende del ayuntamiento de Manresa y la Universitat Politècnica de Catalunya. Este centro inició actividades en 1999, pero fue hasta 2004 cuando el CIDEM (red de centros tecnológicos) lo reconoció como centro tecnológico.
} 


\section{Cuadro 2 \\ Evolución del suelo urbano}

\begin{tabular}{lcl}
\hline \multicolumn{1}{c}{ Año } & 1996 & 2002 \\
\hline Superficie industrial (ha) & 245.6 & 285.1 \\
Superficie servicios (ha) & 127.8 & 153 \\
Superficie comercial (ha) & 33.87 & 42.49 \\
\hline
\end{tabular}

Fuente: Elaboración propia a partir de datos del Idescat, 1996 y 2002.

El área ocupada por el sector comercial aumentó $86,142 \mathrm{~m}^{2}, 25.4 \%$, debido a la proliferación de establecimientos de grandes superficies (hipermercados, centros comerciales), pues de acuerdo con Dupuy (1992: 135), cada día es más frecuente que la ubicación de los centros comerciales se decida por la red de carreteras. Según el estudio, los municipios de Manresa, Navarcles y Sant Hilari Sacalm muestran este fenómeno (es decir, pérdida de establecimientos e incremento de superficie); en este sentido, Sanuy (2005: 154) comenta que el pequeño comercio se encuentra en desventaja competitiva frente a los comercios de grandes superficies. Este fenómeno se aprecia principalmente en el municipio de Manresa, pues entre 1996 y 2002 perdió 118 establecimientos (-0.08\%), en tanto incrementó la superficie en $14,850 \mathrm{~m}^{2}(12 \%)$. No es casual que este mismo fenómeno se observe en Cataluña, donde el número comercios decreció $5 \%$, en tanto que la superficie ocupada aumentó 19 por ciento.

\subsection{Efectos en accesibilidad y movilidad}

\subsubsection{En la evolución del tráfico}

La investigación destaca que la IMD en el tramo de estudio aumentó en los primeros siete años 4,198 vehículos (cuadro 3), como resultado de tres factores principales: el primero y segundo se correlacionan y son el incremento de población en la región y la atracción de actividades económicas que esta zona ha experimentado en los últimos años. Este contexto provoca un mayor intercambio de mercancías que se refleja en el periodo ex post, pues aumentó el número de vehículos pesados que circulan por el Eix Transversal: de 19\% del total del tráfico (en 1998) a $24 \%$ (en 2004). Ahora bien, el tercer factor observado muestra que el Eix Transversal es un atajo para una parte del tráfico internacional de mercancías entre la Península (con punto en Zaragoza) y Europa, pasando por la Junquera, es decir, un atajo en la ruta de la N-II; así, al emplear esta ruta, dicho tráfico afecta directamente el tramo de estudio. 
Cuadro 3

Evolución de la intensidad media diaria

\begin{tabular}{lccccccc}
\hline Año & 1998 & 1999 & 2000 & 2001 & 2002 & 2003 & 2004 \\
\hline IMD & 8,147 & 9,090 & 9,157 & 10,239 & 10,582 & 11,179 & 12,345 \\
\hline
\end{tabular}

Fuente: Elaboración propia a partir de datos de la Dirección General de Carreteres.

\subsubsection{En la evolución de la movilidad intermunicipal}

La accesibilidad favorecida por la construcción del Eix Transversal supone la disminución del tiempo empleado en los desplazamientos intermunicipales, y especialmente provocó el aumento de la movilidad intermunicipal obligada en el periodo ex-post con 4,165 desplazamientos más respecto al año 1996, 15\% (cuadro 4).

\section{Cuadro 4 \\ Evolución de la movilidad intermunicipal}

\begin{tabular}{lrrr}
\hline \multicolumn{1}{c}{ Año } & 1991 & 1996 & 2001 \\
\hline Movilidad intermunicipal por motivo de trabajo & 16,948 & 19,597 & 25,053 \\
Movilidad intermunicipal por motivo de estudio & 7,663 & 7,787 & 6,496 \\
Movilidad obligada intermunicipal (estudio + trabajo) & 24,611 & 27,384 & 31,549
\end{tabular}

Fuente: Elaboración propia a partir de datos del Idescat, 1991-2001.

Los viajes intermunicipales por motivo de estudio disminuyeron entre los ańos 1996 y 2001 en 15\% (1,167 viajes) debido principalmente al aumento de centros de enseńanza en los municipios del territorio analizado. No obstante, se refleja un efecto contrario en los viajes por motivo de trabajo, pues éstos presentan un importante incremento de $28 \%$ entre 1996 y 2001; así, se constata que esta vía influyó de forma determinante en el crecimiento de la movilidad intermunicipal por motivo de trabajo en sus tres primeros años de explotación.

El Eix Transversal favorece que el modo de transporte privado se incremente, pues en los desplazamientos intermunicipales por motivo de trabajo su tasa de utilización pasó de 84\% en 1991 a 94\% en 2001 .

$\mathrm{Al}$ relacionar la movilidad con los sectores productivos, el estudio muestra que los viajes intermunicipales $H B$ (home based) generados por el sector servicios presentaron el mayor crecimiento en el periodo ex-post (lo cual es resultado del espectacular aumento de empleados en dicho sector en el ámbito de estudio). Ahora bien, el sector industrial generó el segundo mayor crecimiento de viajes, no obstante, este sector muestra el tercer 
mayor aumento de trabajadores (seguido del sector de la construcción), como resultado de que la mayoría de las nuevas industrias se instalaron en las ciudades centrales y en sus municipios vecinos, mientras que la actividad de construcción se presenta a lo largo de todo el territorio. Con base en lo anterior, los trabajadores del sector industrial se desplazan más al estar centralizada su actividad en el territorio.

En ese contexto, la focalización de la actividad industrial y la disminución de los tiempos de viajes intermunicipales derivados de la construcción del Eix Transversal, influye en los trabajadores de este sector para realizar el desplazamiento.

De acuerdo con lo anterior, la investigación refleja que los desplazamientos intermunicipales atraídos por los sectores de servicios y de la construcción presentan un mayor aumento en el número de desplazamientos cuando su destino laboral está a menos de 10 minutos, mientras que los del sector industrial mostraron mayor crecimiento (respecto a los otros sectores de actividad) en el lapso que oscila entre 10 y 20 minutos.

\subsubsection{En el ahorro económico de tiempo y carburante}

El Eix Transversal provocó un acercamiento entre la región favorecida, pues el tiempo empleado para ir de Manresa a Vic pasó de 55 a 40 minutos; mientras que de Manresa a Santa Coloma de Farners era de 1:45 minutos, con el Eix Transversal sólo se requiere de 1:15 horas (figura v).

La valoración económica del ahorro en tiempo que ha producido el Eix Transversal se determinó a partir de la IMD de la vía y la valoración económica del tiempo propuesta por Carpintero (2005: 72). Así, la construcción del Eix Transversal indujo un ahorro de tiempo entre 1998 y 2004 valorado en 213'363,337 euros.

Para la valoración económica del ahorro de combustible se empleó el dato del costo de los carburantes del Ministerio de Industria, Turismo y Comercio de España entre 1998 y 2004. El estudio arrojó que el ahorro energético fue de 60’301,502 euros. Estas dos variables (tiempo y carburante) revelan que el ahorro económico inducido por vía entre 1998 y 2004 fue de 273'664,839 euros. Con esto se amortizó en los siete primeros años (1998-2004) 62\% del costo total de construcción del Eix Transversal de Cervera al enlace con la N-II (de 441 millones de euros).

\subsubsection{En la siniestralidad}

La vía presentó una media de 49 accidentes anuales (entre 1998 y 2004) y una media anual de 18 víctimas mortales, en su mayoría resultado de choques frontales. Aplicando el costo social de víctimas mortales, heridos 


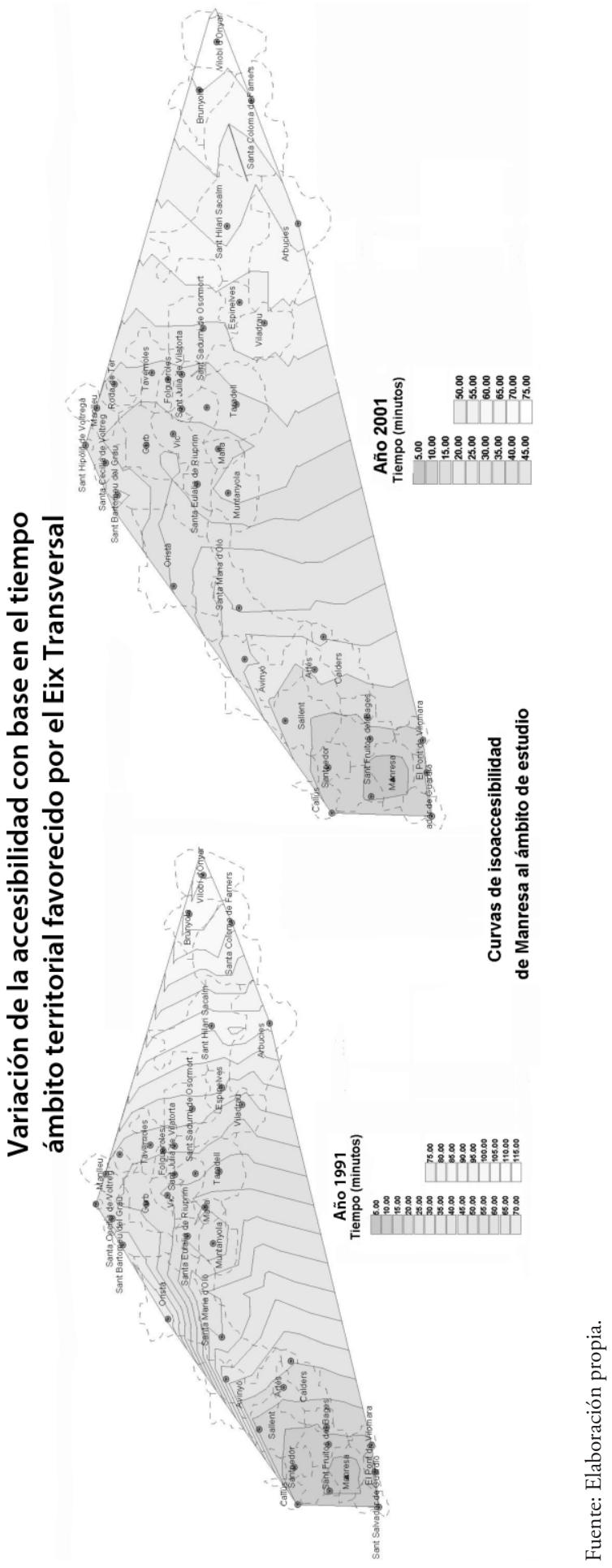


y daños materiales propuesto por Robusté et al. (2000: 4), se obtiene que el costo social producto de accidentes entre 1998 y 2004 asciende a 37’669,139 euros.

En el caso de que no se hubiese construido el Eix Transversal en este territorio, el estudio de GISA (1992, VI: 78)4 estimó que se habría producido una media anual entre 1998 y 2004 de 175 accidentes, con 13 víctimas mortales. Por tanto, el Eix Transversal ha influido en la disminución de accidentes, sin embargo, hay que remarcar el problema de las víctimas mortales en número superior a lo previsto, resultado en su mayoría de percances frontales, pues el Eix es una autovía de dos carriles con calzada única sin mediana.

\subsection{Resultados de la aplicación de las variables de control, politicas de acompañamiento y futuro del Eix Transversal}

Considerando el crecimiento poblacional como indicador del efecto global estructurante de una carretera sobre el medio donde se construye, al aplicar las variables de control en el ámbito territorial que abarca el Eix Transversal se observa que:

- El tamaño de población municipal influye en la atracción de nuevos residentes, pues se observa que $40 \%$ de la población (16,697 habitantes) se asentó en las dos ciudades centrales, mientras que los 19 municipios entre 2,000 y 20,000 habitantes atrajeron $52.4 \%$ (21,692 habitantes). Por último, a los $18 \mathrm{mu}-$ nicipios con menos de 2,000 habitantes llegaron 3,269 nuevos residentes ( 7.8 por ciento).

- La cercanía a una ciudad central influye en el asentamiento de población, pues los siete municipios localizados a menos de 5 $\mathrm{km}$ registraron $24.8 \%$ del crecimiento poblacional, sin contar el crecimiento de Manresa y Vic (6,184 habitantes). En el caso de los 14 municipios localizados entre 5 y $10 \mathrm{~km}$ de una ciudad central, atrajeron $48.1 \%$ (12,006 habitantes), mientras que en los 16 municipios localizados a más de $10 \mathrm{~km}$ se asentó $27.8 \%$ de población restante (6,941 habitantes).

- La cercanía con otra vía de importancia regional (en el caso de estudio la C-16 y C-17) también influye en la atracción de población, pues los 19 municipios situados a menos de $5 \mathrm{~km}$ de cualquiera de estas dos carreteras atrajeron $71 \%$ del crecimiento

\footnotetext{
${ }^{4}$ Empleando los datos de accidentalidad y la imd estimados por gisa para 1992 y 1997, se realizó una proyección lineal determinando la posible accidentalidad en caso de no existir el Eix Transversal entre los ańos de 1998 y 2004.
} 
poblacional (29,530 habitantes), esta cifra es muy alta, pues se consideran las dos ciudades centrales. Sin incluir estas dos ciudades, los 17 municipios restantes atraen 51\% (12,833 habitantes), mientras que los siete municipios localizados entre 5 y 10 $\mathrm{km}$ de ambas vías atrajeron $21 \%$ (5,298 habitantes) y por último, en los 13 municipios a más de $10 \mathrm{~km}$ de estas dos vías se asentó el $27 \%$ restante $(6,830$ habitantes).

- Respecto a la cercanía al Eix Transversal, el estudio refleja que los 24 principales núcleos urbanos de cada municipio localizados a menos de $5 \mathrm{~km}$ del Eix atrajeron $82 \%$ del crecimiento poblacional $(34,111$ habitantes), mientras que en los 15 municipios localizados entre 5 y $10 \mathrm{~km}$ se registró $18 \%$ del crecimiento total de población (7,535 habitantes).

En este sentido, la cercanía al Eix Transversal es el factor más contundente, no obstante, las ciudades centrales y la distancia a otra vía principal también juegan un papel destacado en el impacto de una infraestructura carretera. Respecto a las ciudades centrales, estos núcleos forman dos áreas metropolitanas con los municipios que hay en su entorno (es decir, se observa un asentamiento de población y de actividades económicas, posiblemente por mejores costos de suelo respecto a los de Manresa y Vic).

Cabe señalar el municipio de Santa Coloma de Farners, que si bien es la capital de la comarca de la Selva y crece principalmente en población, no provoca un arrastre de actividad económica debido a la cercanía con la ciudad de Girona y la actividad de su comarca se centra principalmente en su región costera.

Si bien el estudio refleja efectos más o menos difusos, que dependen de la dinámica local, es fundamental que una carretera requiera de ciertas políticas de acompañamiento para aumentar su beneficio social y económico en una región, así, las siguientes políticas son las que se consideran de mayor importancia: 1) rondas construidas en Vic y Manresa, y 2) accesos al Eix Transversal desde los municipios hasta $10 \mathrm{~km}$ (en donde no existía acceso).

Ahora bien, el estudio destaca dos inversiones clave inducidas en las áreas metropolitanas de Vic y Manresa: la Universidad de Vic y los dos centros tecnológicos en Manresa.

Como hemos observado, la mayoría de las variables estudiadas reflejan el efecto positivo de la vía sobre la media de crecimiento en Cataluña, y con base en los resultados obtenidos por la investigación, el Eix Transversal es muy importante para el tráfico de paso y para la estructuración del territorio que afecta. Si bien su diseño inicial es problemático (sólo dos carriles), se prevé el desdoblamiento de 155 kilómetros de la carretera (de 
dos a cuatro carriles, de Cervera a la N-II, tramo que incluye el ámbito de estudio) y cuyas obras ya se han iniciado en algunos tramos.

\section{Efectos socioeconómicos inducidos por la carretera MEX120}

La carretera MEX120 es para el estado de Querétaro de Arteaga una carretera principal, pues es la única vía que comunica de sur a norte su territorio. En los años ochenta la entidad impulsó los proyectos de modernización de su red carretera. Así, el objetivo de la modernización de la carretera MEX120 consistió, por un lado, en reducir tiempos y costos de transporte de personas y bienes; por el otro, aumentar la seguridad y consolidación de la integración del territorio, para contribuir a la descentralización y la reordenación económica. A través de esta investigación se deduce que estos objetivos se han cumplido.

En el ámbito territorial estudiado existen tres regiones con diferencias tanto en orografía como en características sociales y económicas: la primera es la región sur (integrada por los municipios de San Juan del Río, Tequisquiapan y Ezequiel Montes), la más desarrollada; la segunda corresponde a la región del semidesierto, que abarca dos municipios: Cadereyta de Montes, que presenta un nivel de desarrollo ligeramente menor al de los municipios de la región sur, Peñamiller, que debido a las condiciones de orografía y de climatología es uno de los municipios con menor desarrollo. Por último, la región de la Sierra Gorda (integrada por los cinco municipios restantes) es el área con los mayores rezagos económicos y sociales del ámbito territorial de la MEX120.

Debido a las diferencias en los datos estadísticos, el análisis de la etapa previa a la modernización de la carretera, en algunas variables se analiza a partir de 1989 y en otras después de 1990, y el estudio de la etapa de modernización abarca hasta 1995; mientras que el periodo de explotación abarca de 1995 a 2000 y en algunas variables, dependiendo de su disponibilidad, el estudio se extiende hasta el año 2005.

\subsection{Efecto en la demografía}

La población favorecida por la carretera MEX120 en el periodo de modernización de la vía (entre 1990 y 1995) aumentó en 55,653 habitantes, $14 \%$ (figura vi), en tanto que en el periodo de explotación (entre 1995 y 2005) la población se incrementó en 80,226 habitantes (18\%), la principal causa de esto fue el crecimiento natural, el nivel estatal no supera la tasa de crecimiento de la población del área de estudio en el periodo $e x-$ post, pues es de 16 por ciento. 


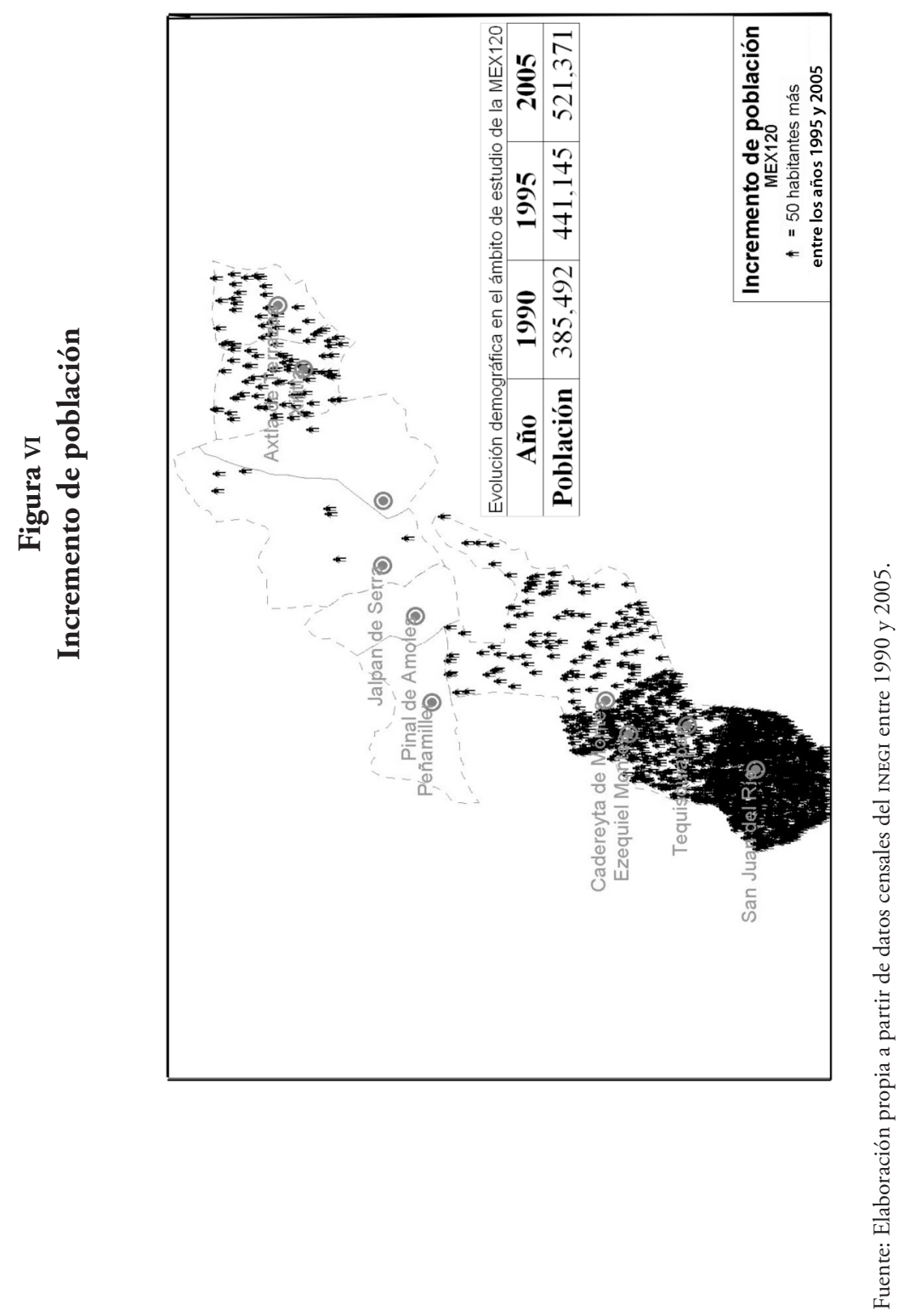


El análisis develó que el mayor incremento de población en el periodo ex-post se presentó en la ciudad central y en los municipios cercanos a ésta. El desarrollo económico de la región sur atrae población, pues $31 \%$ de su crecimiento (12,506 habitantes) es producto de la inmigración proveniente de municipios de los estado de Querétaro, México e Hidalgo. Uno de los principales problemas que presentaba la región serrana era la alta emigración (principalmente hacia Estados Unidos), sin embargo, el estudio demuestra que la mejora en accesibilidad ha facilitado el desarrollo económico de la región, que junto con una mejor la calidad de vida ha contenido la emigración que presentaban los municipios de esta área. En todo caso, la emigración oscila en niveles inferiores a los presentados antes de la modernización, lo que no sucede en los ámbitos político-territoriales superiores, pues en éstos se supera el nivel del periodo ex-ante.

\subsection{Efectos en la actividad económica}

\subsubsection{En los sectores de producción}

Otro de los principales efectos indirectos inducidos por esta carretera fue el desarrollo de las actividades económicas. El impulso en la zona se confirmó al comparar las tasas de crecimiento con los niveles político-territoriales superiores, pues el total de establecimientos en el ámbito territorial aumentó a 5,171: 67\% (figura VII), mientras que en el ámbito estatal aumentó 35\%. El sector industrial en el periodo ex-ante se incrementó en 735 establecimientos, mientras en el periodo ex-post aumentó 664 establecimientos (50\%), estableciéndose principalmente en las regiones sur y del semidesierto; en el ámbito estatal también mostró un mayor desarrollo en el periodo ex-ante (79\%), sin embargo, en el periodo ex-post sólo incrementó 5\% frente al 50\% del área de estudio. Si bien las regiones ya industrializadas son las que presentan mayor atracción, en las áreas con mayor rezago (como la serrana) este crecimiento tiene un efecto directo y significativo en la creación de puestos de trabajo y en las actividades económicas indirectas.

El sector comercial en el periodo ex-ante aumentó 1,792 establecimientos, mientras que en el periodo ex-post creció 2,469 establecimientos, esto representa $59 \%$, mientras el nivel estatal incrementó 16 por ciento.

El sector servicios en el periodo -ante aumentó 1,047 establecimientos, y en el ex-post se incrementó en 2,038 establecimientos (90\%), mientras que en el ámbito estatal aumentó $76 \%$. El desarrollo de este sector en la región serrana ha sido fundamental en el alivio a la pobreza, pues presenta el mayor aumento en número de establecimientos de los tres sectores estudiados (225). 


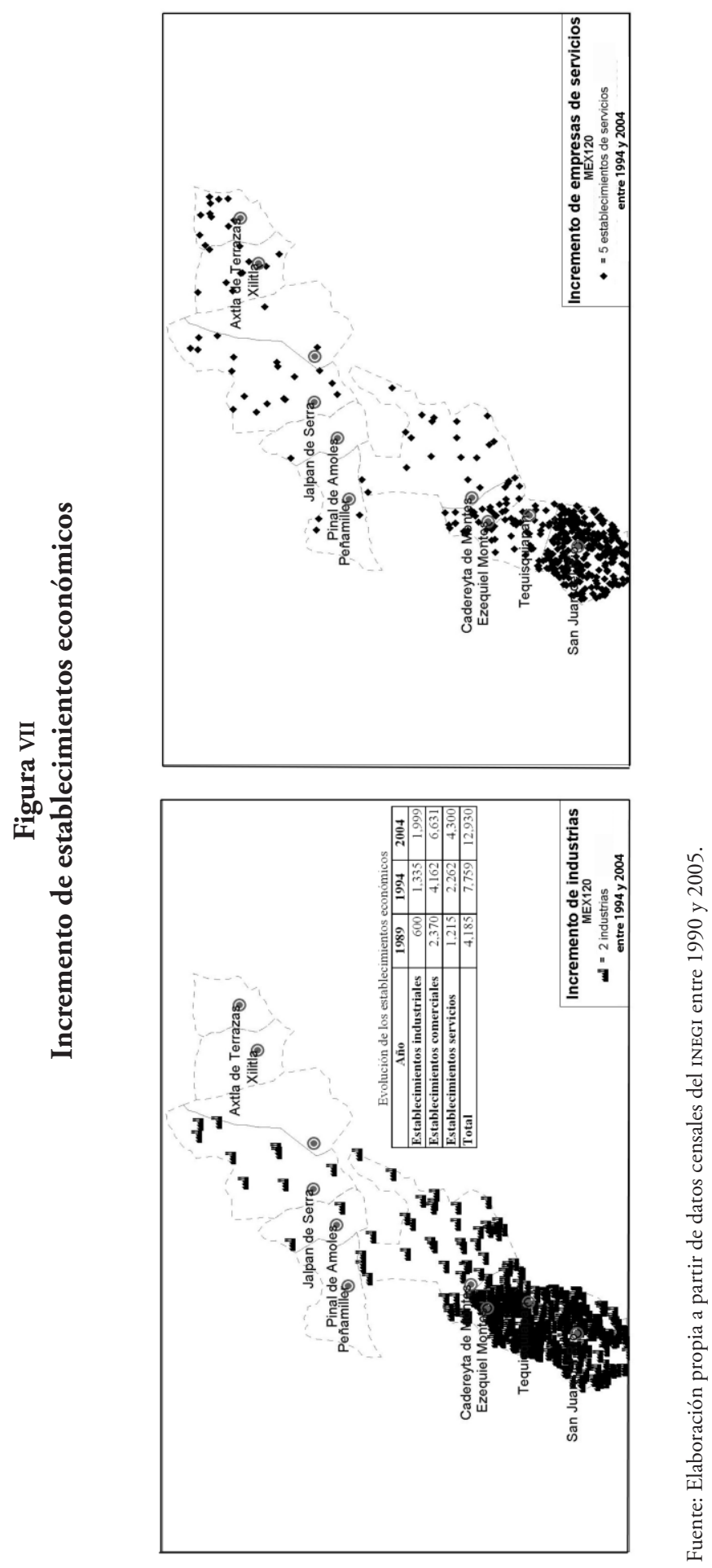




\subsubsection{En la ocupación}

El incremento de establecimientos económicos provocó la creación de nuevos puestos de trabajo, así lo refleja esta investigación pues, en el periodo ex-ante aumentó en 11,066 (figura VIII), mientras en el periodo ex-post incrementó 35,194 empleos, esto representa un aumento de 26\%, en tanto que en el ámbito estatal presentó 19 por ciento.

Por sector de actividad el estudio reveló que la población ocupada en el sector primario descenció en todos los municipios; la pérdida de puestos de trabajo en este sector se debe, por un lado, a la implementación de nuevas tecnologías en las explotaciones de las regiones con mayores recursos económicos, y por otro, a que en las regiones menos desarrolladas, debido a la falta de subsidios, asistencia técnica y por el uso de tecnologías tradicionales, repercute en los precios del producto; por ello, les resulta más difícil que sus precios sean competitivos, y al no ser rentables estas explotaciones tienden a abandonarse. Aun así, la región serrana continúa teniendo el mayor porcentaje de su población activa ocupada en el sector primario (alrededor de 40\%, es decir, 12,153 en el ańo 2000), cuya producción sirve principalmente para autoconsumo y comercio local. El sector industrial, en el periodo ex-ante experimentó un aumento de 3,817 empleos, mientras en el periodo ex-post se incrementó en 13,742 (53\%), siendo el municipio de San Juan del Río y los cercanos a éste los que presentaron el mayor aumento de trabajadores. Una de las causas es que esta región se beneficia del rápido acceso que le proporciona la carretera MEX120 a la autopista MEX57. Una vez más, el ámbito territorial en el periodo ex-post supera la tasa de crecimiento en el ámbito estatal (44 por ciento).

El sector de la construcción aumentó el número de empleos en el periodo ex-ante en 1,427 (12\%), mientras que en el periodo ex-post alcanzó los 15,903 en el año 2000 (2,796 trabajadores, 21\%). El ámbito estatal no muestra la misma tendencia que el área de estudio, pues su tasa de crecimiento en el periodo ex-ante fue de 5.2\%; mientras que en el periodo ex-post fue de 4.7 por ciento.

El sector servicios presentó el mayor desarrollo de los cuatro sectores de actividad estudiados. Éste aumentó 20,424 ocupados más en el periodo ex-post (58\%). Ahora bien, en el ámbito estatal en el periodo ex-post aumentó 37\%, por ello se observa un mayor crecimiento en la zona de estudio, provocado principalmente por el desarrollo del sector turístico, sobre el que se habla más adelante.

Si bien la investigación demuestra que la modernización de la carretera MEX120 indujo indirectamente el desarrollo de las actividades económicas, aún existe un rezago tangible en la región serrana, pues el 


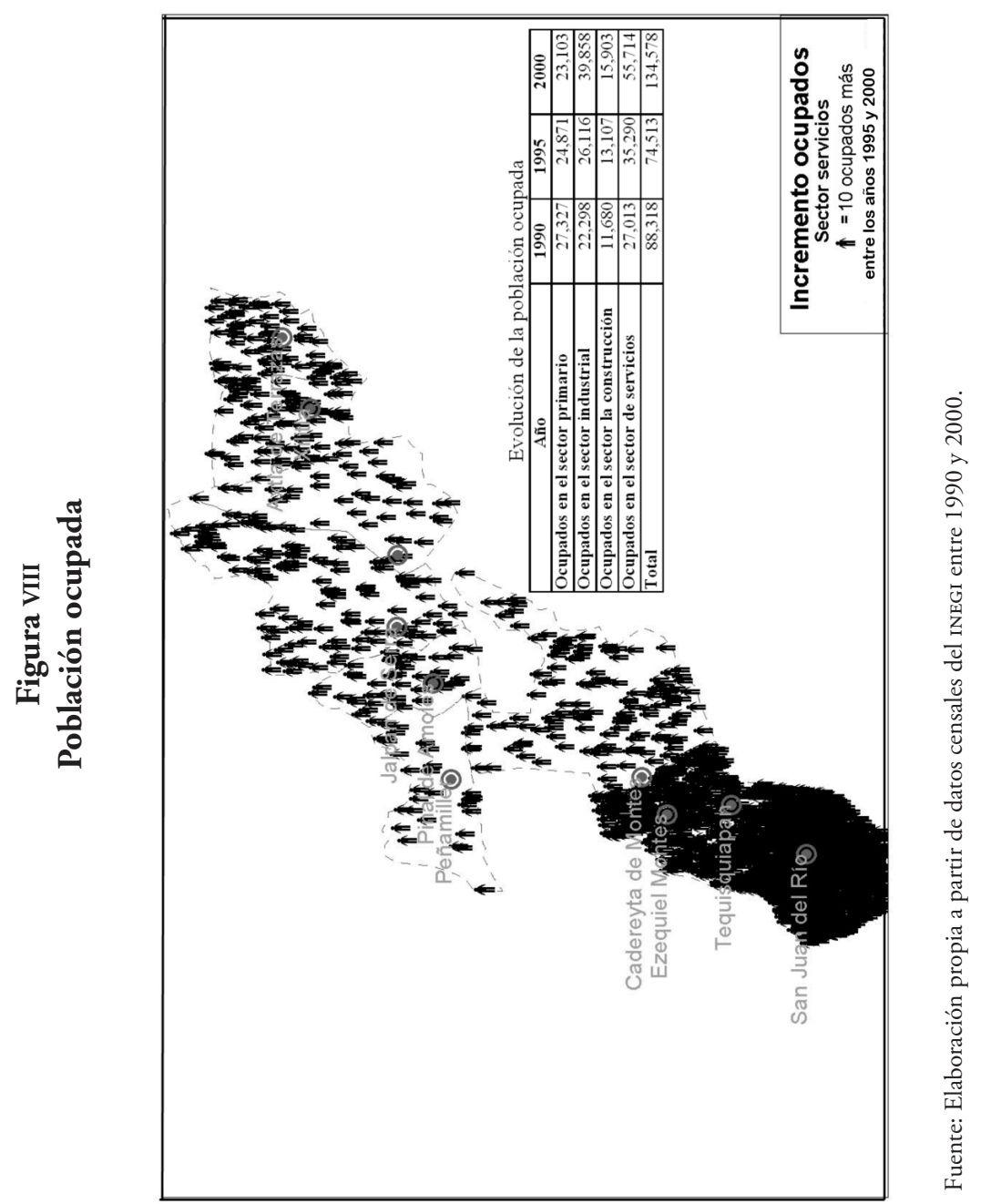


gobierno no promueve suficientes proyectos de inversión en esta zona, y además se decanta en favorecer regiones más desarrolladas, por ejemplo, la región sur.

\subsubsection{En las entidades financieras}

En relación con la evolución del número de oficinas bancarias, cabe destacar que entre 1990 y 1995 se instalaron 10 nuevas oficinas (de 21 en 1990 a 31 en 1995), mientras que en el periodo ex-post se instalaron 29 oficinas, alcanzando 60 en el año 2005 (la mayoría de los municipios duplicó su número de oficinas). De este modo, el área de estudio supera la tasa de crecimiento registrada en todo el estado en el periodo ex-post: $94 \%$ y $84 \%$, respectivamente.

\subsection{Efectos sociales}

\subsubsection{En la construcción de viviendas}

La evolución de la vivienda de nueva construcción en el ámbito de estudio, muestra que su desarrollo responde principalmente al crecimiento poblacional. En el periodo ex-ante aumentó en 14,827 viviendas (figura IX), mientras en el periodo ex-post se construyeron 14,138. El ámbito estatal también muestra un menor número de vivienda de nueva construcción en el periodo ex-post $(97,673$ viviendas respecto a 120,843 del periodo ex-ante). No obstante, la tasa de crecimiento en el área de estudio supera la del estado ( $17 \%$ frente a 14 por ciento).

Llegados a este punto, es necesario recordar lo que menciona Carpintero (2005: 93) respecto a las políticas que se diseñan para aliviar la pobreza en los países en vías de desarrollo. Este investigador menciona que en la mayoría de los casos éstas siguen alguno de los siguientes enfoques: el primero, aportar estrategias que traten de mitigar las necesidades básicas de la población más desfavorecida, especialmente en lo que se refiere a servicios básicos, salud y educación; el segundo es un enfoque indirecto, pues confía en que los beneficios derivados del crecimiento económico terminen llegando a la población más desfavorecida en forma de oportunidades de trabajo, mejora del nivel de renta, entre otros.

Trasladando el primer enfoque al ámbito de estudio, éste refleja que el porcentaje de viviendas con agua potable se incrementó después de la modernización de la carretera MEX120, pues en el año 1995, 40\% de las viviendas contaban con este servicio, y en el año 2000 se alcanzó a cubrir $76 \%$. Buena parte de las líneas de conducción de agua potable transcurre a un costado de la vía (principalmente en la región serrana), beneficiando 


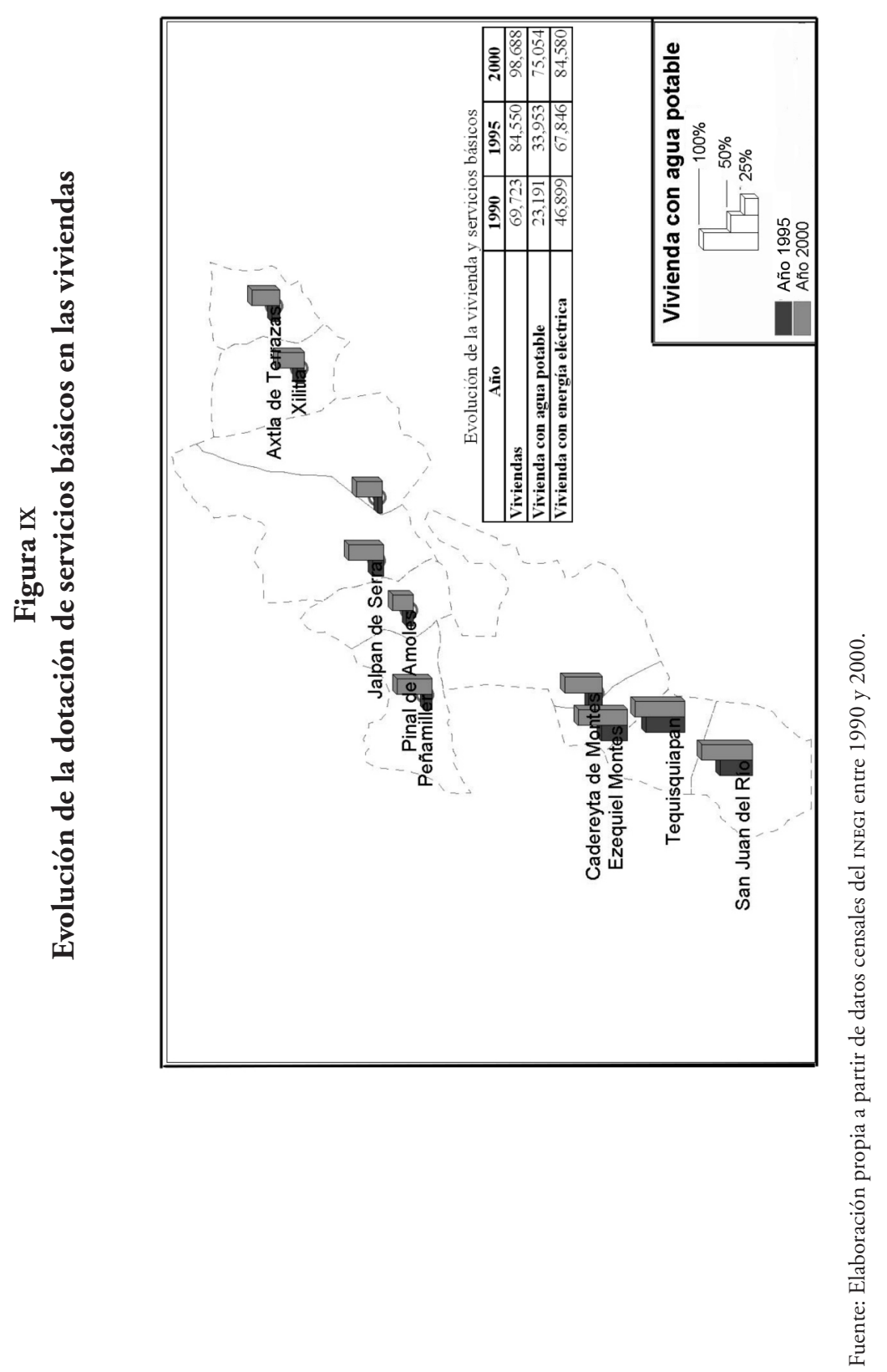


a la población y posibilitando el establecimiento de actividades económicas. De hecho, si no se hubiera realizado esta inversión en la mejora de los servicios básicos, se puede decir que aumentaría el fenómeno migratorio que se presentaba en el periodo ex-ante en el área de estudio. La investigación también refleja que es en los municipios con menor dotación de servicios básicos, por ejemplo de agua potable en las poblaciones de Xilitla, Jalpan y Pinal de Amoles, donde precisamente aumentó la emigración en el periodo ex-post. Es probable que de no haber mejorado la dotación de servicios básicos en el ámbito de estudio, la emigración en la región serrana hubiese sido mayor a la observada actualmente.

\subsubsection{En la atracción turistica}

Para analizar la actividad turística, se optó por examinar la evolución de las plazas hoteleras (la suma del número total de habitaciones de todos los hoteles). La investigación refleja que la actividad turística se ha visto impulsada: alcanzó 2,536 plazas en el año 2005 (figura x). Si bien el principal aumento de plazas hoteleras se presenta en la región sur, esta actividad ya se ofertaba antes de la modernización, al formar parte del corredor turístico Santiago de Querétaro-San Juan del Río-Tequisquiapan. No obstante, es notable el crecimiento en los municipios de la región serrana (principalmente en Jalpan de Serra con 144 plazas más), consideramos que son dos las posibles causas: la primera, la MEX120 ha influido acortando los tiempos de viaje; la segunda responde a la promoción turística de la Reserva de Biosfera Sierra Gorda. De este modo, contar y promocionar sitios de interés turístico aunado a la mejora de la accesibilidad de la región, han impulsado el desarrollo de este sector. Así se demuestra al comparar las tasas de crecimiento del número de plazas hoteleras con los ámbitos político-territoriales superiores, pues en el territorio beneficiado por la carretera MEX120, el número de plazas hoteleras aumentó entre 1995 y 2005 en 155\%, en tanto que, en el ámbito estatal se incrementó $47 \%$ en el mismo periodo.

\subsection{Efectos en accesibilidad y movilidad}

\subsubsection{En la evolución del tráfico de la MEX120}

La modernización de la carretera MEX120 influyó de forma determinante en la atracción de tráfico en toda la longitud de la vía. El mayor tránsito se localiza en la región sur, es decir, entre San Juan del Río y Ezequiel Montes (cuadro 5), el cual aumentó entre 1995 y 2001 en 1,271 vehículos (25\%). En las regiones del semidesierto y de la Sierra Gorda la IMD es 


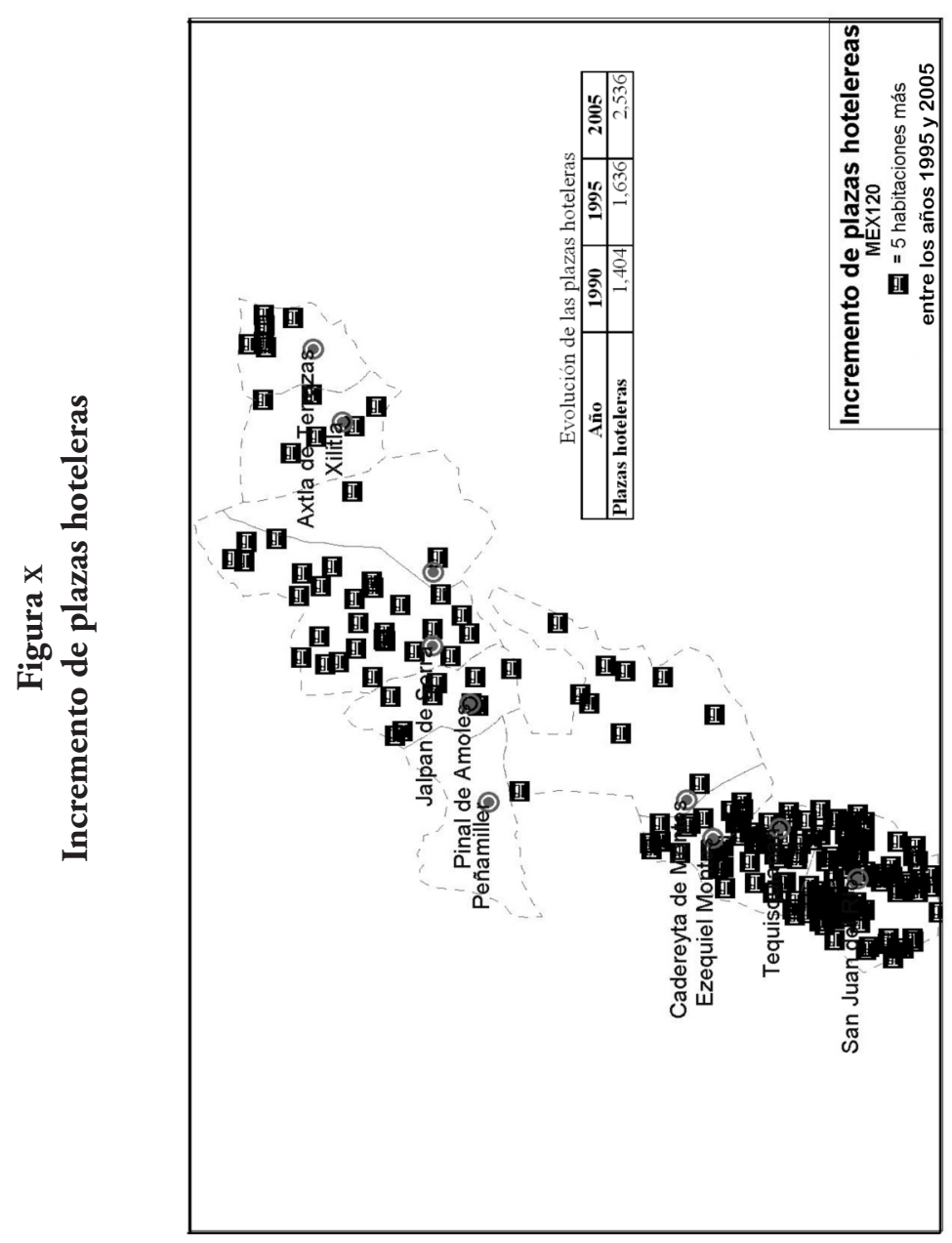

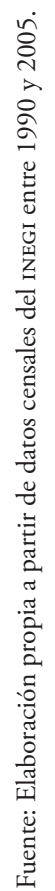


Cuadro 5

Evolución de la IMD

\begin{tabular}{lrr}
\hline \multicolumn{1}{c}{ Año } & 1995 & 2001 \\
\hline Región sur & 5,105 & 6,376 \\
Región del semidesierto & 1,313 & 1,730 \\
Región serrana & 707 & 866 \\
Vehículos pesados & & \\
Región sur & 1,123 & 1,658 \\
Región serrana & 148 & 200 \\
\hline
\end{tabular}

Fuente: Elaboración propia a partir de comunicación personal de aforos de tráfico en la MEX120, Secretaría de Comunicaciones y Transportes (México).

menor, no obstante, estas regiones también incrementaron su tráfico en el periodo ex-post. En el tramo que cruza la región del semidesierto (entre Ezequiel Montes y Peñamiller), la IMD aumentó en 417 vehículos (32\%), por su parte, en la región serrana se incrementó en 166 vehículos (23 por ciento).

La menor IMD en la región del semidesierto y serrana respecto a la región sur es resultado de tres razones: la primera es que en la región sur se localiza mayor número de habitantes; la segunda se debe a la baja relación de vehículos por habitante que existe en la zona (4.5 vehículos por cada cien habitantes en la región serrana, mientras que en la región sur es de 14.2); y la tercera es que el mayor número de industrias están instaladas en la región sur. En consecuencia, esta investigación refleja precisamente que es en esta región por donde transita el mayor número de vehículos pesados (cuadro 5).

Otro punto que es importante destacar es que en los seis ańos posteriores a la modernización de la vía, el porcentaje de vehículos pesados que circulan por esta carretera aumentó notablemente, sobre todo en la región sur, donde la tasa de vehículos pesados que oscilaba en $22 \%$ en el año 1995, aumentó a 26\% en el 2001, en tanto que en la región serrana, pasó de 21 a 23 en el mismo periodo. De este modo, al aplicar el factor de equivalencia a vehículos ligeros se observa que la IMDeq de la región sur en 1995 era de 6,243 vehículos, mientras que en 2001 alcanza los 8,040, en tanto que en la región serrana era de 1,511 vehículos en 1995 y de 1,920 en el año 2001.

\subsubsection{En el ahorro económico en tiempo y carburante inducido por la carre- tera MEX120}

Es importante destacar que el ahorro de tiempo después de la modernización de la MEX120 entre San Juan del Río y Xilitla es de 96 minutos 
(figura XI). Por ello, se valoró económicamente este ahorro empleando el tráfico que circula por la carretera y el valor social del tiempo propuesto por Cervini (2006: 60), pues es el costo más actual valora la hora en México en 31.1 MXP/hora. La modernización de la carretera supuso un ahorro de tiempo a sus usuarios en los años de 1995 a 2003 de 499'168,026 pesos. A la vez, la investigación valora económicamente el ahorro de combustible empleando los precios de carburante del Compendio Estadístico del Sector Energía, de la Secretaría de Energía de México. De este modo, la modernización de la carretera permitió un ahorro económico en carburante en los años de 1995 al 2003 de 209'051,403 pesos.

El ahorro económico total (tiempo y combustible) inducido por la MEX120 en los años de 1995 a 2003 es de 708’219,429 pesos. El costo total de las obras de modernización fue de 245.2 millones de pesos. Así, empleando estas dos variables se observa que en cinco años esta vía ya ha amortizado su costo de modernización.

\subsection{Resultado de la aplicación de las variables de control, políticas de acompañamiento y futuro de la carretera MEX120}

Al aplicar las variables de control al ámbito territorial favorecido por la carretera MEX120 se observa que:

- En relación con la cercanía de otra vía principal, los municipios localizados en la proximidad de la autopista MEX57 y la carretera MEX69 (San Juan del Río, Tequisquiapan y Jalpan de Serra) presentan un mayor desarrollo respecto a sus municipios vecinos.

- Acerca de la cercanía de una ciudad central, el municipio de San Juan del Río juega este papel en el área de estudio, registrando un considerable desarrollo en el periodo ex-post, el cual se transmite a su entorno (es decir, a los municipios de Tequisquiapan y Ezequiel Montes). En este sentido, en dichos municipios se observa un intenso asentamiento tanto de actividades económicas como de población, lo cual se atribuye a la mejor calidad de vida que ofrece dicha región (es decir, dotación de servicios básicos, de educación, de empleo, de salud, entre otros).

- En cuanto a la distancia del principal núcleo de población de cada municipio con la carretera MEX120, en ocho de los 10 municipios la vía cruza parte de la zona urbana. No obstante, se observa que en éstos la vía influye en el desarrollo urbanístico. En este sentido, destacamos la influencia de la vía en el municipio de San Juan del Río al propiciar el desarrollo del parque industrial Valle de Oro (en el kilómetro 2 de la MEX120). Aho- 


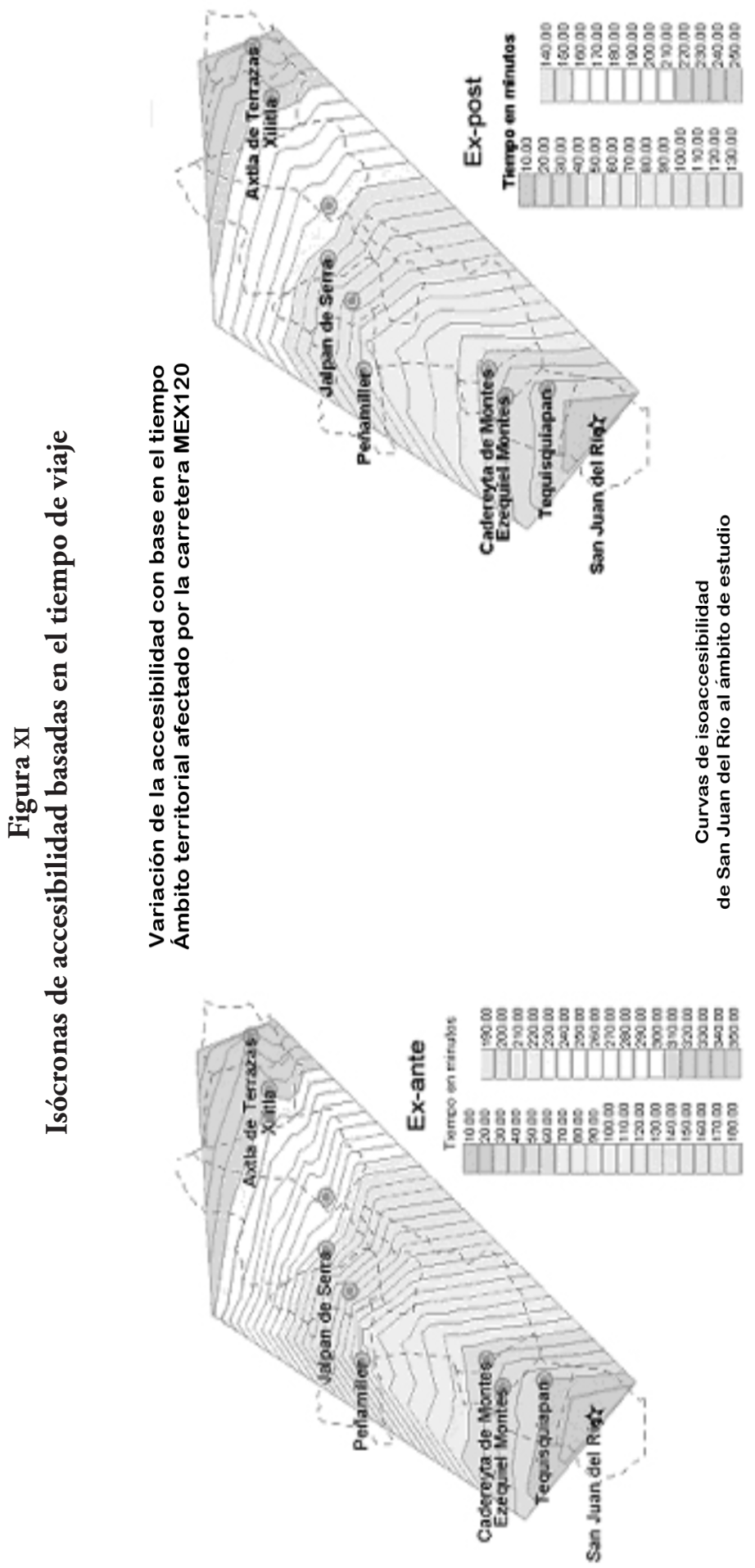


ra bien, los dos municipios restantes (Peñamiller y Axtla de Terrazas), localizados entre 5 y $10 \mathrm{~km}$ de la carretera MEX120, registraron tasas de crecimiento inferiores a las de la media del área de estudio.

- Respecto del tamaño poblacional, no se observa una clara relación entre el número de habitantes y los niveles de crecimiento, a excepción de la ciudad central, la cual registró el mayor aumento de población en la zona de estudio en el periodo expost.

Las políticas de acompañamiento que han aumentado el beneficio económico y social de la región favorecida por la carretera MEX120, y que se consideran las más importantes, son: construcción y mejoras de los caminos de acceso a la carretera y secundarios (es decir, mejora de la accesibilidad a las comunidades rurales); y modernización de la carretera MEX69.

Ahora bien, la investigación destaca cuatro acciones clave inducidas en el ámbito de estudio por parte del Estado: 1) dotación de servicios básicos (agua, energía eléctrica, drenaje); 2) modernización de la autopista MEX57; 3) creación de campos universitarios en San Juan del Río y Jalpan de Serra; y 4) decreto de la Reserva de Biosfera Sierra Gorda.

Debido al desarrollo inducido por la modernización de la MEX120, en el año 2005 el gobierno del estado de Querétaro proyectó la ampliación de la vía en toda su longitud, incrementando el ancho de calzada de seis a 12 metros en la región sur, mientras que en algunos tramos de la región montañosa se planea la construcción de un carril adicional (dos carriles de subida y uno de bajada en los tramos más críticos). Estas obras ya han comenzado a realizase en el tramo de San Juan del Río-Tequisquiapan.

\section{Conclusiones}

La investigación refleja que las dos vías analizadas han inducido un efecto inmediato de desarrollo socioeconómico en sus respectivos territorios, las principales coincidencias y diferencias que el estudio arroja se exponen a continuación.

En cuanto al efecto demográfico, el Eix Transversal de Cataluña cumple con su objetivo de incidir en repoblar la Cataluña Central, ya que la vía en el periodo ex-post ha atraído población a lo largo de todo su recorrido, registrando un notable crecimiento demográfico resultado de la atracción de inmigrantes de origen nacional y extranjero. Por su parte, el desarrollo económico que indujo la carretera MEX120 ayudó a contener la emigración que presentaba la región serrana (la de mayor atraso socioeconómico), y a su vez, propició la atracción de inmigración (nacional) 
en los municipios más desarrollados (los de la región sur). Así, el estudio desveló que mientras en el país desarrollado la vía atrae población inmigrante, en el país en vías de desarrollo el crecimiento económico inducido por una infraestructura carretera contiene o disminuye la emigración en las zonas rurales, mientras que las ciudades centrales (más desarrolladas) en ambos casos, se convierten en focos de atracción de población.

Con respecto al desarrollo de establecimientos económicos, la investigación resalta que éstos se incrementaron notablemente al mejorar la accesibilidad. El mayor o menor desarrollo de cada sector depende de las características y localización geográfica de cada municipio, por ejemplo, en el caso del sector industrial, se observa su crecimiento en la mayoría de los municipios de los dos territorios beneficiados. No obstante, a corto plazo el mayor aumento de establecimientos se presenta en las zonas ya consolidadas en este sector, principalmente en las ciudades centrales y en los municipios cercanos a éstas. Ahora bien, el sector servicios de igual forma incrementa sus establecimientos a lo largo del recorrido de cada una de las vías, y a la vez se observa que el crecimiento se presenta más intenso en las ciudades centrales y en los municipios que han dirigido su oferta de servicios en la rama del turismo.

En los establecimientos comerciales el estudio demostró que éstos muestran la mayor discrepancia en su evolución en los dos territorios comparados, pues en el caso de la carretera MEX120 esta actividad cuenta con el mayor número de establecimientos y, al mismo tiempo, presenta un notable aumento de éstos. Ahora bien, en el ámbito de estudio del Eix Transversal se aprecia un ligero crecimiento de los establecimientos de este sector y un notable incremento de su superficie (que se percibe sobre todo en las ciudades centrales y en los municipios cercanos a éstos), lo cual es resultado de la proliferación de los establecimientos de grandes superficies. Esto es resultado del nivel de desarrollo en cada ámbito, pues si la actividad comercial es la que define la mayor cantidad de núcleos, y por el contrario, la industria y los servicios se hallan escasamente representados, será un reflejo de una sociedad poco modernizada (Ferrer, 1992: 55). Así, en el ámbito del Eix Transversal el sector servicios prima sobre el industrial y el comercial, y por su parte, el ámbito de la MEX120 muestra que el sector comercial está por encima de los demás (lo que confirma lo mencionado por Ferrer). Sin embargo, el estudio refleja que a partir de la modernización de la carretera el sector industrial y de servicios poco a poco está ganando terreno frente al sector comercial.

En relación con la ocupación en general, la investigación reflejó un notable aumento en el periodo ex-post en los dos ámbitos de estudio, así, el incremento de accesibilidad ha impulsado la creación de nuevos puestos de trabajo. En el caso del sector primario, éste presenta una disminu- 
ción en su número de empleos, siendo mayor en el ámbito de la MEX120, tal vez por esto la región presenta un abandono del campo a causa del alto costo de la tecnología, la cual es necesaria para disminuir los precios y poder competir en el mercado, lo que incita a la población a ocuparse en sectores como la construcción o los servicios. Estos dos últimos sectores de actividad son los que presentan los mayores incrementos de población ocupada en el periodo ex-post en los dos ámbitos territoriales. Hay que destacar el aumento del empleo en el sector servicios en algunos municipios rurales, pues la mejora de la accesibilidad ha permitido una mayor afluencia de visitantes, lo cual permite explotar sus atractivos turísticos con mayor beneficio.

Por su parte, la ocupación en el sector de la construcción responde principalmente al desarrollo inmobiliario. En este sentido, en el ámbito del Eix Transversal se observa un notable crecimiento de la vivienda tanto primaria como secundaria, mientras que en el caso de la MEX120 el aumento de la vivienda responde sobre todo al crecimiento natural de la población. En este punto, una de las diferencias que se observaron entre los dos territorios es que en el ámbito territorial de la MEX120, en el periodo ex-post se incrementó notablemente el número de viviendas con servicios básicos (sobre todo en los municipios rurales), lo cual, aunado al impulso económico propiciado por la carretera, ayudó a disminuir la emigración que se presentaba en la región serrana en el periodo ex-ante.

La investigación desveló otra de las diferencias que se presentan entre los dos territorios, la cual refleja las diferencias de condiciones económicas que prevalecen en las dos regiones. Si bien los dos ámbitos territoriales incrementan sus centros universitarios en el periodo ex-post, sólo en el caso del Eix Transversal se produce el asentamiento de los dos centros de innovación tecnológica ya mencionados.

La mejora en accesibilidad ha inducido la participación en el trabajo, el cual es más valioso en las regiones que presentan mayores atrasos, pues la oferta de puestos aumenta la actividad de la población y disminuye el desempleo, por lo que la población se beneficia incrementando su capital económico. Este aumento de capital en los dos ámbitos de estudio se refleja en la evolución del sector financiero, pues a lo largo del recorrido de cada una de las dos vías se instaló un gran número de oficinas bancarias, y fue superior el crecimiento de estas sucursales en el periodo ex-post respecto al ex-ante.

Ahora bien, la investigación refleja que si bien en los dos ámbitos territoriales se observa un aumento de oficinas bancarias, el nivel económico en cada uno de ellos nos arroja la principal disimilitud ya que, mientras que en el ámbito territorial de Eix Transversal existen 1.11 oficinas bancarias por cada mil habitantes, en el de la carretera MEX120 esta relación 
pasa de 0.05 oficinas bancarias por cada mil habitantes a 0.11 en el periodo ex-post.

Cabe destacar que la mejora del poder adquisitivo de la población beneficiada en ambas vías se puede ver reflejada en la evolución del parque vehicular. Así, el estudio muestra que en el periodo ex-post los dos ámbitos de estudio aumentaron notablemente su número de vehículos. Ahora bien, se observa que al igual que en las oficinas bancarias, en el ámbito territorial de la carretera MEX120, la relación vehículo por habitante es mucho más baja respecto al ámbito del Eix Transversal, ya que la relación se incrementa de 62 vehículos por cada cien habitantes en el periodo $e x-$ ante a 71 vehículos en el periodo ex-post. Mientras que en el ámbito de la carretera MEX120 la relación en el periodo ex-ante es de 4.15 vehículos por cada cien habitantes, ésta alcanza 10.7 vehículos en el periodo ex-post. Esta diferencia se debe a la disparidad en el poder adquisitivo entre los dos países.

Ahora bien, este aumento de vehículos que se presenta en los dos ámbitos territoriales, ha propiciado una mayor movilidad en las dos regiones. En este sentido, la intensidad media diaria de cada una de las vías se ha incrementado en más de $20 \%$ en sus primeros seis años de explotación. La aplicación en ambos casos de las isócronas de accesibilidad simple basadas en el tiempo nos muestran gráficamente cómo una infraestructura viaria acerca a los habitantes, lo cual impulsa las relaciones tanto sociales como económicas de la región. Al mismo tiempo la investigación valoró económicamente los ahorros en tiempo y carburante inducidos por cada una de las vías a sus usuarios. El resultado muestra que en estas vías se presentó un importante ahorro económico, al emplear estas dos variables. Por un lado, el ahorro en tiempo y carburante inducido por el Eix Transversal amortizó en sus primeros siete años de explotación más de $60 \%$ de su costo de construcción, y por el otro, la carretera MEX120, al emplear estas mismas variables, amortizó su costo cinco ańos después de su modernización. La diferencia en tiempo en cuanto a la amortización de las obras radica en que el Eix Transversal es una vía que se construyó por completo, incluyendo obras de alto costo económico como túneles y viaductos. En el caso de la modernización de la carretera MEX120 no se construyó ninguna infraestructura de gran envergadura.

Para el ámbito territorial del Eix Transversal se dispuso de información referente a la evolución de la movilidad obligada intermunicipal, por lo que se analizó. El estudio reflejó un considerable aumento de la movilidad por motivo de trabajo en el periodo ex-post, la cual fue notable en los alrededores de las ciudades centrales. Así, se considera que el incremento de accesibilidad propicia una mayor dispersión en el territorio de los centros laborales o del lugar de residencia. Ahora bien, el Eix Transversal, 
al ser una vía más rápida que las preexistentes en su territorio, redujo el tiempo empleado en los desplazamientos, lo cual permite que la distancia de viaje pueda incrementarse sin afectar el tiempo. Lo anterior, aunado a la comodidad y a la seguridad de la vía, son los principales factores al momento de elegir esta vía en la movilidad intermunicipal obligada.

En todo caso, un factor común basado en el éxito socioeconómico inducido por las dos infraestructuras carreteras estudiadas, junto al aumento de tráfico registrado en cada una de estas vías, propició en ambas carreteras el desarrollo de proyectos de ampliación.

Cabe destacar como uno de los puntos más representativos, que esta investigación reflejó que la mayor parte de las variables analizadas presentan mayores tasas de crecimiento en los ámbitos territoriales beneficiados por estas vías, respecto de sus niveles político-territoriales superiores. ${ }^{5} \mathrm{De}$ esta manera se llega a la conclusión de que las infraestructuras carreteras propician e impulsan el desarrollo social y económico del territorio. De hecho, las diferencias observadas son resultado de la disimilitud en cuanto al nivel económico en cada una de las dos regiones, ya que mientras el PIB per cápita, según el Banco Mundial, en el año 2006, en España era de 27,340 dólares, en México era de 7,468.

$\mathrm{Al}$ aplicar las variables de control se observa que tanto las ciudades centrales como la cercanía a otras vías de importancia provocan un efecto multiplicador en el territorio. En ambas áreas de estudio la investigación refleja que las ciudades centrales funcionan como focos de desarrollo, influyendo en el crecimiento de los municipios cercanos. Ahora bien, en las regiones en donde se intercepta la vía de estudio con otra carretera importante, los municipios cercanos a estos nodos muestran un desarrollo considerable. Además, la investigación muestra que es en estos nodos donde se localizan las ciudades centrales de los dos ámbitos de estudio (Manresa, Vic y San Juan del Río); asimismo se observa que el municipio de Jalpan de Serra (el cual contiene la intersección de la carretera MEX120 con la MEX69) se ha convertido en el centro económico de la región de la Sierra Gorda. Por lo anterior, se considera que los municipios que se localizan cerca de una ciudad central o de otra vía principal poseen mayores posibilidades de desarrollo. En este sentido, se observa que aunque la vía induce una dispersión territorial de las actividades en ambas regiones, las ciudades centrales continúan ejerciendo su papel jerárquico al atraer gran parte de las nuevas actividades de la región. En todo caso, para obtener una mayor difusión territorial a la observada, se requiere que el Estado desarrolle políticas de inversión que considere pertinentes en la

${ }^{5}$ La Comunidad Autónoma de Cataluńa en el caso del Eix Transversal, y los estados de Querétaro de Arteaga y San Luis Potosí en el caso de la carretera MEX120. 
región, con el fin de atraer actividad económica (y población) a los municipios localizados entre las ciudades centrales.

Si bien el periodo analizado muestra el efecto a corto plazo de estas dos infraestructuras sobre su entorno, la capacidad de inducción o posibilidad de desarrollo que ofrece una infraestructura carretera dependerá de las condiciones inherentes en cada municipio y en cada región, además de su disposición para generar proyectos de inversión. Por ello, este trabajo propone dos líneas de investigación: la primera, hacer un estudio en el ámbito municipal sobre las condiciones previas a la puesta en operación de estas carreteras, analizando los proyectos y acciones que han realizado los ayuntamientos en el periodo de construcción y explotación de cada vía para determinar qué o cuáles acciones o proyectos son más beneficiosos y rentables para el desarrollo; la segunda es prolongar este estudio en el tiempo, lo que determinará cuáles han sido los efectos a largo plazo, y según sea el caso, hasta qué momento el desarrollo de los ámbitos territoriales beneficiados mantienen un mayor crecimiento respecto al de sus niveles político-territoriales superiores.

\section{Agradecimientos}

El autor agradece a Rosa Junyent i Comas su apoyo, comentarios y aportaciones en la realización de este trabajo, así como las observaciones de los dos dictaminadores anónimos en la revisión temprana del documento.

\section{Bibliografía}

Badoe, Daniel y Eric Miller (2000), “Transportation-Land-Use Interaction: Empirical Findings in North America, and their Implications for Modelling", Transportation Research Part D, 5, Washington, D.C., pp. 235-263.

Banco Mundial (2006), "Estadísticas e indicadores: tablas con perfiles de países", www.bancomundial.org/datos/datos.html, 15 de mayo de 2007.

Banister, David y Joseph Berechman (2000), Transport Investment and Economic Development, ucL Press, Londres.

Berechman, Joseph (1995), "Transport Infrastructure Investment and Economic Development: A Review of Key Analytical and Empi- 
rical Issues", en David Banister (ed.), Transport and Urban, Development, Chapman and Hall, Londres, pp. 17-35.

Berechman, Joseph y Robert Paaswell (2001), "Accessibility improvements and local employment: An empirical analysis", Journal of Transportation and Statistics, 4 (2/3), Washington, D. C., pp. 49-66.

Burmeister, Antje y Guy Joignaux (1997), Infrastructures de transport et territoires: Approches de quelques grands projets, l'Harmattan, París.

Caja de Ahorros y Pensiones de Barcelona La Caixa (2006), Anuario Económico de España, Servicio de Estudios de La Caixa, Barcelona, www.estudios.laCaixa.es/anuarioeconomico, septiembre de 2007.

Carpintero, Samuel (2005), Infraestructuras de transporte y desarrollo económico, Cátedra Abertis, Barcelona.

Cervero, Robert (1999), “Tracking Accessibility: Employment and Housing Opportunities in the San Francisco Bay Area", Environment and Planning A, 35, Londres, pp. 1259-1278.

Cervero, Robert (2003), "Road expansion, urban growth, and induced travel: a path analysis", Journal of the American Planning Association, 69 (2), Chicago, pp. 145-162.

Cervini, Héctor (2006), "El costo social del tiempo en México", Centro de Estudios para la Preparación y Evaluación Socioeconómica de Proyectos (CEPEP), México, www.cepep.gob.mx/documentos/, 7 de mayo de 2007.

Dubois-Taine, Geneviève (1991), Les boulevards urbains, contribution à une politique de la ville, Presses de l'École Nationale des Ponts et Chaussées, París.

Dunn, Edgar Jr. (1954), The location of agricultural Production, University of Florida Press, Gainesville.

Durán-Fernández, Roberto (2008), "Regional Convergence, Infrastructure and Industrial Diversity in Mexico", Transport Studies Unit, Working Paper Ref. 1031, Oxford University Centre for the Environment, Oxford. 
Dupuy, Gabriel (1992), L'urbanisme des réseaux. Théories et méthodes, Armand Colin, París.

Dupuy, Gabriel (1995), Les territoires de l'automobile, Anthropos, París.

Ferrer, Manuel (1992), Los sistemas urbanos, Síntesis, Madrid.

Forkenbrock, David y Norman Foster (1990), "Economic Benefits of a Corridor Highway Investment", Transportation Research, 24A, Washington, D.C., pp. 303-312.

GISA (Gestió d'Infrastructures, s.A.) (1992), Estudi socio-econòmic: l'Eix Transversal de Catalunya, Generalitat de Catalunya-Departament de Política Territorial i Obres Públiques-gisA-Institut del Medi Ambient i Ciències Socials, Barcelona.

Hanson, Susan (1986), The geography of urban transportation, Guilford, Nueva York.

Holl, Adelheid (2004), "Manufacturing Location and Impacts of Road Transport Infrastructure: Empirical Evidence from Spain”, Regional Science and Urban Economics, 34, Ámsterdam, pp. 341-363.

Idescat (Institut d'Estadística de Catalunya) (2007), "Base de dades de municipis i comarques", www.idescat.cat, mayo de 2007.

Idescat (2008), "Padrón continuo de población”, www.idescat.cat, junio de 2008.

INEGI (Instituto Nacional de Estadística, Geografía e Informática) (2007), "Resultados del conteo nacional de población y vivienda", www. inegi.gob.mx, mayo de 2007.

INEGI (Instituto Nacional de Estadística, Geografía e Informática) (2007), "Censos económicos", www.inegi.gob.mx, mayo de 2007.

Isard, Walter (1956), Location and Space Economy, Technology Press, Cambridge.

Junta de Andalucía (2000), Socio-Economic Benefits of the A92 Motorway in Spain, Research Report, Junta de Andalucía-Conserjería de Obras Públicas y Transportes, Sevilla. 
Leralta-García, Javier (1991), Madrid. Ciudad y coche, La Librería, Madrid.

London School of Economics (2000) PNR2000, Research proyect and study by London School of Economics.

Lösch, August (1954), The economics of Location, Yale University Press, New Haven.

Ministerio de Industria, Turismo y Comercio de España (2007), "El petróleo: informes mensuales", www.mityc.es/Petroleo/Seccion/ Precios/Informes/InformesMensuales/, octubre de 2007.

Navarre, Françoise y Rémy Prud'Homme (1984), "Le rôle des infrastructures dans le développement régional”, Revue d'Economie Régionale et Urbaine, 1, París, pp. 5-21.

Pascal, Bérion (1998), "Analyser les mobilités et le rayonnement des villes", Les Cahiers Scientifiques du Transport, 33, Lyon, pp. 109-127.

Papí, José, Pawel Stelmaszczyk y Brendan Halleman (2006), "The SocioEconomic Benefits of Roads in Europe”, European Union Road Federation, Bruselas, www.irfnet.eu/media/doc/2808_erf_ sebs_030306_final.pdf, 23 de septiembre de 2006.

Plassard, François (1978), Les autoroutes et le developement regional, pulEconomica, París.

Rephann, Terance y Andrew Isserman (1994), "New highways as economic development tools: an evaluation using quasi-experimental control group matching methods", Regional Science and Urban Economics, 24 (6), Ámsterdam, pp. 723-751.

Robusté, Françesc, Magin Campos y Andrés Monzón (2000), Els comptes del transport de viatgers a la Regió Metropolitana de Barcelona 1998, Autoritat del Transport Metropolità, Barcelona.

Sachs, Wolfgang (1992), For love of the automobile: Looking Back into the history of our desires, University of California Press, Berkeley.

Sanuy, Françesc (2005), Informe Sanuy: Defensa del petit comerç i critica de "La Caixa", La Campana, Barcelona. 
Sutton, Christopher (1999), "Land Use Change Along Denver's I-225 beltway", Journal of Transport Geography, 7, Manchester, pp. 31-41.

Universitat de Valencia (2000), Valoración económica de los efectos de la Autopista A7 en la Comunidad Valenciana, Universitat de ValenciaAumar-Instituto de Economía Internacional, Valencia.

Urarte, Jesús (1980), Interrelaciones, Urbanismo-Transporte, ETs de Ingenieros de Caminos, Canales y Puertos-upc, Barcelona.

Von Thünen, Johann Heinrich (1826), Der Isolierte Staat in Beziehung auf Landwirtschaft und Nationalökonomie, Hamburgo.

Wang, Junfeng (2002), Searching for the urban development pattern, University of North Carolina at Pembroke, www.uncp.edu/mpa/ papers/professionalpapers/searching_for_the_urban_development_pattern.pdf, 7 de febrero de 2005.

Weber, Alfred (1909), Üeber den Standort der Industrien, Tübingen.

Wingo, Lowdon y Harvey Perloff (1961), "The Washington Transportation Plans technics or politics?”, Papers in Regional Science, 7 (1), Auckland, pp. 249-262.

Recibido: 24 de diciembre de 2008 Reenviado: 12 de junio de 2009 Aceptado: 25 de junio de 2009

Saúl Antonio Obregón-Biosca. Es doctor por la Universidad Politécnica de Cataluña (UPC) y licenciado por la Universidad Autónoma de Querétaro (UAW). Actualmente labora como profesor-investigador en la División de Estudios de Posgrado de la Facultad de Ingeniería de la UAQ. En el ámbito internacional, es miembro del equipo de investigación del Laboratorio de Estudios Sociales de la Ingeniería Civil de la upc. Su línea de investigación actual se ubica en la ingeniería de las redes de infraestructuras del territorio, en dos ámbitos: el primero, las infraestructuras de transporte como elemento vertebrador del territorio; el segundo, tecnologías emergentes en la captación de información de tráfico. 